\title{
Bilateral Inhibition Generates Neuronal Responses Tuned to Interaural Level Differences in the Auditory Brainstem of the Barn Owl
}

\author{
Ralph Adolphs \\ Division of Biology, Caltech, Pasadena, California 91125
}

I investigated the neural algorithms by which neurons gain selectivity for interaural level difference in the brainstem of the barn owl (Tyto alba). Differences in the timing and in the level of sounds at the ears are used by this owl to encode, respectively, azimuthal and vertical position of sound sources in space. These two cues are processed in two parallel neural pathways. Below the level of the inferior colliculus, all neurons in the pathway that processes level differences show responses to this cue that are monotonic, and thus not selective for a particular level difference. Only in the inferior colliculus, which contains a map of auditory space, are neurons sharply tuned to specific interaural level differences. How are these response properties generated from those of the nuclei that provide input to the inferior colliculus?

I show that the posterior subdivision of the nucleus ventralis lemnisci lateralis (VLVp) projects bilaterally to the lateral shell of the central nucleus of the inferior colliculus, the input stage to the map of auditory space. Both these nuclei are part of the pathway that processes interaural level differences. Manipulations of the responses in VLVp affected the responses to level differences in the inferior colliculus; responses to time differences were unaffected. By systematically increasing or decreasing neural activity in VLVp, I show that the VLVp on each side provides inhibition to the colliculus at large level differences. This results in a peaked response that is tuned to level differences in the inferior colliculus. Some cells in the lateral shell of the inferior colliculus appear to receive direct GABAergic inhibition from VLVp. I suggest that this circuitry and the algorithms it supports are the neural substrates that allow the barn owl to exploit level differences for computation of sound source elevation.

[Key words: sound localization, interaural intensity difference, inferior colliculus, lateral lemniscus, GABA, inhibition]

Received Sept. 25, 1992; revised Feb. 24, 1993; accepted Mar. 1, 1993.

I thank J. Mazer, E. Knudsen, J. Pearson, T. Takahashi, and M. Konishi for comments on a previous version of the manuscript, and $\mathrm{M}$. Konishi for helpful suggestions on later drafts. The manuscript benefitted from the criticisms of two anonymous reviewers. T. Takahashi, S. Volman, and M. Konishi provided help and encouragement at various stages of the experiments. J. Mazer wrote all the computer programs for stimulus presentation and analysis on the Masscomp 5600 computer. R.A. is a Howard Hughes Medical Institute Fellow. This work was in part supported by NIH Grant DC00134-14 to M. Konishi.

Correspondence should be addressed to Ralph Adolphs, Department of Neurology, The University of Iowa College of Medicine, lowa City, IA 52242-1053.

Copyright (c) 1993 Society for Neuroscience $0270-6474 / 93 / 133647-22 \$ 05.00 / 0$
Two striking features of sensory systems are the presence of neurons that encode complex and highly selective stimuli, and the organization of such neurons into topographic maps. In the visual and somatosensory systems of many species, maps of sensory space are generated directly by the preservation of the receptor epithelium's topography. A neural representation of space based on auditory cues, on the other hand, must be centrally synthesized by the computation of binaural disparities in the timing and the level of sounds (Konishi, 1986). In the barn owl, a vertical asymmetry in the external ears and facial feathers generates interaural level differences (ILD) that vary systematically with the elevation of the sound source for frequencies above $3 \mathrm{kHz}$ (Coles and Guppy, 1988; Moiseff, 1989b). Interaural time differences (ITD) are due to the separation of the ears along the horizontal axis. Together, these two cues are used by the owl to localize accurately the direction from which a sound emanates in both elevation and azimuth. The spatial acuity of the barn owl's auditory system enables it to catch small, rustling prey in complete darkness.

Anatomical and physiological evidence indicates that interaural level differences and time delays are processed in parallel and functionally independent pathways, referred to as the intensity pathway and the time pathway (Moiseff and Konishi, 1983; Sullivan and Konishi, 1984; Takahashi et al., 1984). The intensity pathway consists in all nuclei that are terminal fields of the cochlear nucleus angularis; neurons in angularis encode sound level by their rate of firing. The time pathway consists in all nuclei that are terminal fields of the first nucleus sensitive to binaural time differences, nucleus laminaris. Nucleus angularis and nucleus laminaris project to different regions of the central nucleus of the inferior colliculus (ICc), the "shell" and "core," respectively (Takahashi and Konishi, 1988a).

The time and intensity pathways converge in the lateral shell of the ICc (Adolphs, 1988; Takahashi and Konishi, 1988a; Takahashi et al., 1989), which provides the sole ascending auditory input to the external nucleus of the inferior colliculus (ICX), the site of a map of auditory space (Knudsen, 1983; Wagner et al., 1987). The ICx contains neurons that selectively respond to unique combinations of time and level differences (Moiscff and Konishi, 1983; Fujita and Konishi, 1989); as a consequence, these neurons have auditory receptive fields with clearly delimited vertical and horizontal borders (Knudsen and Konishi, 1978).

Some cells in the lateral shell of ICc, and all cells in the ICx, are exclusively binaural and will not respond to large level differences that favor either ear. This results in a response to varying ILD that shows a sharp peak. The tuning to ILD can be 


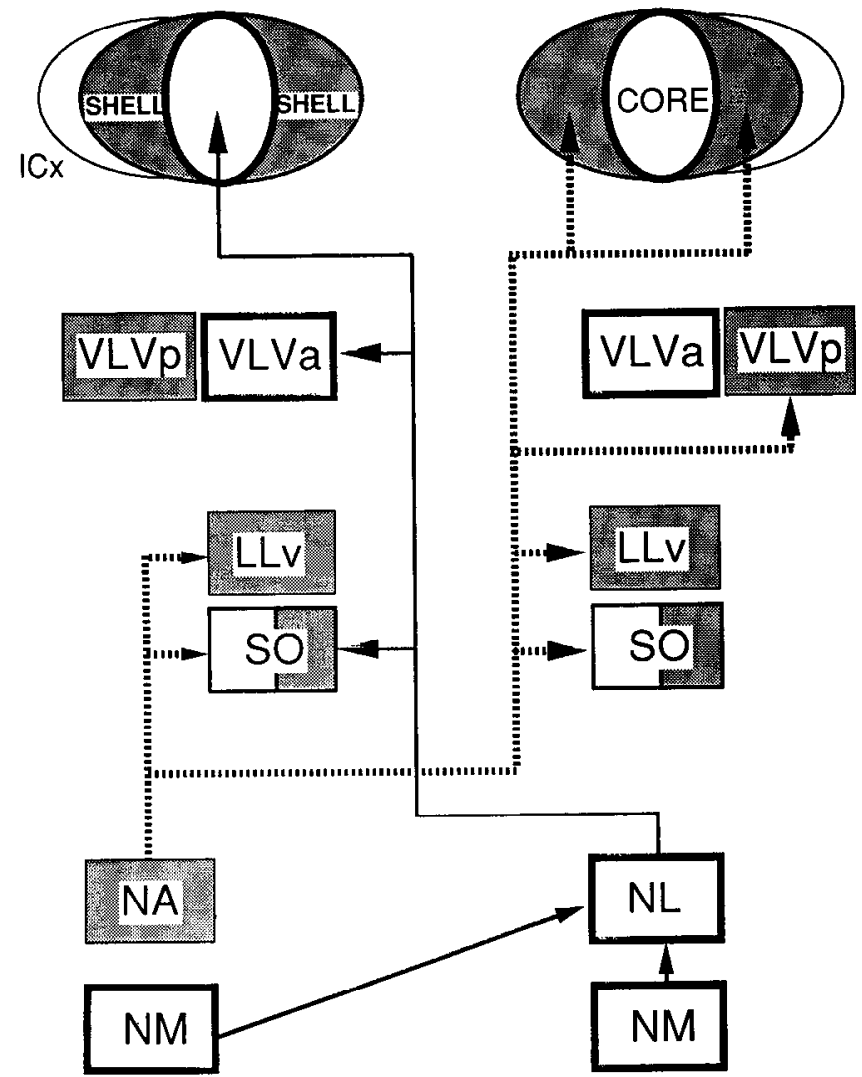

Figure 1. Schematic of the intensity pathway (shaded boxes and broken lines), and the time pathway (open boxes and solid lines). Boxes denote nuclei, and lines their connections. For the inferior colliculus, subdivisions are represented by ellipses. Only the terminal fields of the left $N A$ and of the right $N L$ are shown for clarity as they delineate, respectively, the intensity and time pathways. Nucleus $S O$ is a terminal field of both NA and NL and has separate subdivisions that participate in each of the two pathways. $N M$, nucleus magnocellularis; $N A$, nucleus angularis; $N L$, nucleus laminaris; $S O$, nucleus of the superior olive; $L L v$, nucleus lemnisci lateralis, pars ventralis; $V L V p$, nucleus ventralis lemnisci lateralis, pars posterior; $V L V a$, nucleus ventralis lemnisci lateralis, pars anterior; $I C x$, external nucleus of the inferior colliculus. Core and shell refer to the subdivisions of the central nucleus of the inferior colliculus.

used to code for elevation in bicoordinate sound localization (Moiseff, 1989a,b).

The intensity pathway is shown schematically in Figure 1. The second-order nucleus, nucleus ventralis lemnisci lateralis, pars posterior $(\mathrm{VLVp})$, receives a direct and probably excitatory projection from the contralateral nucleus angularis (Takahashi and Konishi, 1988b; Takahashi and Keller, 1992) and an inhibitory input that appears to arrive from the VLVp of the opposite side via the commissure of Probst (Takahashi, 1988; Takahashi and Keller, 1992). As a result, neurons in VLVp are sensitive to binaural stimuli: they are excited by sounds loud at the contralateral ear via a direct connection from nucleus angularis, and they are inhibited by sounds loud at the ipsilateral ear via an indirect inhibitory projection. This results in a response curve that is a sigmoid function of ILD (Moiseff and Konishi, 1983; Manley et al., 1988).

Previous experiments on the functional role of the nuclei that process ILD have been carried out with paradigms similar to the ones presented here. Takahashi et al. (1984) injected the local anesthetic lidocaine into nucleus angularis while recording responses to auditory stimuli in ICx. They found that only the tuning to level differences of the ICx neuron was affected; the responses to ITD were unaffected. This finding showed that the two processing streams are functionally independent, and that nucleus angularis participates only in the intensity pathway.

More recent experiments (Takahashi, 1988; Takahashi and Keller, 1992) showed that the inactivation of one VLVp with a local anesthetic will disinhibit the cells in the opposite VLVp; this suggests that the two VLVps inhibit each other. But what computations take place upstream from VLVp? Where does the nucleus project, and how might it contribute to the synthesis of responses in higher stations? I address these issues in the experiments reported here.

\section{Materials and Methods}

Physiology. The techniques used were similar to ones reported earlier (Manley et al., 1988). I used 13 adult barn owls (Tyto alba) of both sexes that had been bred in captivity in the laboratory of $M$. Konishi (Caltech). Individuals were initially anesthetized with ketamine hydrochloride $(100 \mathrm{mg} / \mathrm{ml}$, Ketaset, Aveco; $0.1 \mathrm{ml} / \mathrm{owl} / \mathrm{hr})$ and diazepam (5 $\mathrm{mg} / \mathrm{ml}$, Diazepam Injection, Steris Labs; $0.1 \mathrm{ml} / \mathrm{owl} / \mathrm{hr}$ ) and then maintained under ketamine anesthesia. The anesthetized owl was wrapped in a soft leather jacket, and the skull was held in a fixed stereotaxic position in which the plane defined by the center of the ear bars and the ventral surface of the palatine ridge was tilted $45^{\circ}$ downward from the horizontal (Wagner et al., 1987). A small craniotomy and retraction of dura allowed microelectrode and micropipette penetrations of the brain. A local anesthetic was applied around the edges of the scalp wound. Experiments typically lasted $12-20 \mathrm{hr}$, after which the craniotomy was closed with acrylic and the scalp was sutured. Antibiotic ointment (Neosporin, Burroughs Wellcome) was applied on the wound and the owl was returned to an individual cage. At least $3 \mathrm{~d}$ of recovery, during which the animal was closely monitored and fed, was allowed between experiments.

All recording was done with glass electrodes filled with Wood's metal plated with gold and platinum. Exploratory physiology used a singlebarreled glass electrode that had been filled with Wood's metal. During the experiments, triple-barreled glass pipettes $(1.2 \mathrm{~mm}$ o.d., $0.6 \mathrm{~mm}$ i.d.; A-M Systems Inc.) were used, in which one barrel was filled with Wood's metal and plated with gold and platinum at the tip, and the other two barrels were filled with solutions of drugs for iontophoresis. Triple-barreled electrodes had an outer tip diameter of 5-15 $\mu \mathrm{m}$ with a gradual taper. After plating, the recording barrel impedance was 0.5 $3.0 \mathrm{M} \Omega$ at $1 \mathrm{kHz}$. A backing current of $-5 \mathrm{nA}$ was applied to the drug barrels to prevent leakage. Small electrolytic lesions were made at the end of a recording session to allow subsequent histological identification of the recording site.

For larger, pressure injections of drugs or of tracers, a glass pipette gradually tapering to a $10-20 \mu \mathrm{m}$ tip was glued to the metal tip of a 5 $\mu l$ Hamilton syringe with epoxy (Takahashi et al., 1984). Injection electrodes were positioned stereotaxically after localizing the target with a Wood's metal electrode. Multiunit potentials could be recorded through the syringe for verification. In experiments involving multiple injections, there was at least 1 hr of recovery time between injections. Up to four series of injections were performed on each side per owl. Additional injections produced lesions that prevented complete recovery of neuronal responses. The positions of the structures injected were verified histologically by these lesions. All injections, unless otherwise

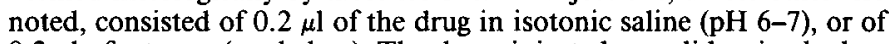
$0.2 \mu \mathrm{l}$ of a tracer (see below). The drugs injected were lidocaine hydrochloride ( $4 \%$ buffered, Xylocaine, Astra Pharmaceuticals), bicuculline methiodide (BMI; 5 mM aqueous, pH 7.0, Sigma), GABA (0.5 м aqueous, pH 7.0, Sigma), or muscimol (3 mm aqueous, pH 7.0, Sigma).

Drugs were iontophoresed in $0.9 \%$ saline solution at acidic pH. A continuous positive current of $20 \mathrm{nA}$ was used for iontophoresis of BMI (5 mM, pH 3.0-3.5) or GABA (0.5 M, pH 3.0-3.5) (Caspary et al., 1985; Mueller and Scheich, 1988; Fujita and Konishi, 1991). After iontophoresis, a backing current of -5 nA was applied to prevent leakage.

Auditory stimuli consisted of tone or pseudorandom noise bursts (1/ $\mathrm{sec}, 100 \mathrm{msec}$ duration, $5 \mathrm{msec}$ rise-fall time) delivered through calibrated earphones (Takahashi and Konishi, 1986; Wagner et al., 1987) that provided power over the entire frequency range to which neurons 
respond (1-10 kHz). Stimuli of varying ILD were presented at the neuron's preferred ITD, and the average binaural intensity (ABI) was typically set to $20 \mathrm{~dB}$ above the neuron's threshold. ILD-response functions were generally obtained at a fixed ABI; only in a few cases was ILD presented by holding the sound level at the excitatory ear constant and varying the level at the ear that inhibited responses (Irvine, 1987). In a few cases, stimuli of varying ITD were presented at the optimal preinjection ILD of the neuron. All varying stimuli were presented in randomized order.

Only single neuron activity is presented here. Spikes were amplified, time stamped, and stored for subsequent analysis. All stimulus presentation and data acquisition were done either by a PDP 11/40 computer controlling a digital tone-synthesizer and a pair of digital attenuators or by a Masscomp 5600 computer that generated tones or noise that was subsequently fed through the same pair of digital attenuators. All spike data points represent the average value of 5-10 repetitions of the measurement; error bars indicate the standard error of the mean.

Normal histology. Following physiological experiments, the owl was overdosed with pentobarbital ( $8 \mathrm{cc}$, i.m., of Nembutal, $50 \mathrm{mg} / \mathrm{ml}$, Abbot Laboratories), exsanguinated with PBS (pH 7.4), and fixed by transcardial perfusion with $1 \%$ paraformaldehyde and $1.25 \%$ glutaraldehyde (in $0.1 \mathrm{M}$ phosphate buffer, $\mathrm{pH}$ 7.4). The fixative was cleared with ice-cold $10 \%$ sucrose in $0.1 \mathrm{~m}$ phosphate buffer. Brains were removed, blocked stereotaxically in a transverase plane parallel to that of the electrode penetrations, sunk in $20 \%$ sucrose overnight, and cut frozen into 30 $\mu \mathrm{m}$-thick sections on a sliding microtome. Sections were stained with neutral red and/or processed for histochemical staining for acetylcholinesterase (Karnovsky and Roots, 1964; Adolphs, 1991, 1993) and examined for electrode tracks and lesion sites from the injection experiments.

Tracer studies. Five owls were used in studies of the projections from lemniscal nuclei to the inferior colliculus (see Table 1). Each owl was also used in physiological experiments. All tracers were injected under physiological guidance. The lectin from Phaseolus vulgaris (PHA-L; Vector Labs; Gerfen and Sawchenko, 1983) was simultaneously pressure injected $(0.2 \mu \mathrm{l})$ and iontophoresed (3-5 $\mu \mathrm{A}$ pulsed on/off $5 \mathrm{sec}$ for a total duration of $20 \mathrm{~min}$ ) as a $2.5 \%$ buffered aqueous solution; owls were subsequently perfused as above except that the fixative consisted of $4 \%$ paraformaldehyde with no glutaraldehyde.

Fluorescently labeled latex microspheres (Lumafluor, New City, NY; Katz et al., 1984) were pressure injected in undiluted volumes of 0.2$0.4 \mu \mathrm{l}$; owls were perfused normally. Sections were subsequently examined for neurons retrogradely labeled with the microspheres under a fluorescence microscope equipped with a motorized stage and labeled neurons were manually digitized onto an image of the section.

The B-subunit of cholera toxin (List Laboratories; Ericson and Blomqvist, 1988) was pressure injected as $0.2 \mu \mathrm{l}$ of a $1 \%$ buffered aqueous solution; owls were perfused normally. In the case of PHA-L and cholera toxin, sections were later processed with a secondary antibody to the tracer and then processed by the avidin-biotin ABC method (Vector Labs) in conjunction with horseradish peroxidase/diaminobenzidine histochemistry.

Definition of terms. Interaural level difference, ILD, is defined as the sound pressure level (in dB SPL) at the contralateral ear minus the level at the ipsilateral ear, to have a uniform terminology for measurements on both sides of the brain. Average binaural intensity, ABI, is the numerical average of the sound pressure level at each ear. ILD was varied in two ways. "ILD at constant ABI" decreased the level at one ear while increasing the level at the other ear by the same numerical amount (in $\mathrm{dB}$ ). "ILD at varying $\Lambda \mathrm{BI}$ " held the level at one ear constant while varying the level at the other ear only; $A B I$ and ILD both changed in this case. The ILD at constant ABI method was used unless otherwise noted.

\section{Results}

\section{Connectivity of physiologically studied areas}

Table 1 lists the owls that were used for hodological experiments. Retrograde tracers were injected into the inferior colliculus, and anterograde tracers into VLVp, to study the connectivity between the two nuclei. The injection pipette was always positioned under physiological guidance. Multineuron responses were recorded through the injection pipette to confirm structures to be injected.

\begin{tabular}{lll}
\hline Table 1. & Owls used for anatomy & \\
$\begin{array}{l}\text { Owl } \\
\text { number }\end{array}$ & Tracer & Structure injected \\
\hline 438 & Cholera toxin & Lateral shell \\
395 & Cholera toxin & Lateral shell \\
391 & Red beads & Lateral shell \\
391 & Green beads & Medial shell \\
438 & PHA-L & VLVp \\
451 & PHA-L & VLVp \\
\hline
\end{tabular}

Figures 2 and 3 show that VLVp provides bilateral input to the lateral shell of ICc. The lectin tracer PHA-L was simultaneously injected and iontophoresed into the VLVp on one side (two owls). This technique resulted in both anterograde label of terminal fields of VLVp neurons, and of weakly retrogradely labeled cell bodies that project to VLVp. The pattern of anterograde label seen suggests that labeled terminal fields are situated in the shell of ICc. Both medial and lateral parts of the shell are labeled, but the core is not. Label was also seen in the contralateral VLVp (Fig. 4) in a pattern that suggests that the ventral portion of one VLVp projects to the dorsal portion of the VLVp on the other side, in agreement with the recent findings by Takahashi and Keller (1992). Very weak retrograde label was also observed in the contralateral nucleus angularis (data not shown).

To confirm these projections, the B-subunit of cholera toxin was injected into the ICc in two owls in sites that included, but were not restricted to, the lateral shell. The results from one such injection are shown in Figure 5. Retrogradely labeled cell bodies were clearly visible in the VLVp on both sides; other structures that were retrogradely labeled (data not shown) were the contralateral nucleus angularis, the contralateral nucleus of the superior olive, the core of the contralateral ICc, and the ipsilateral nucleus lemnisci lateralis pars ventralis (LLv). All of these projections arc consistent with previous reports (Adolphs, 1988; Takahashi and Konishi, 1988a; Takahashi et al., 1989); a bilateral projection from VLVp to the IC is reported here for the first time. Frequency is mapped in the anteroposterior dimension of VLVp, and in the dorsoventral dimension in the ICc. Label was found in restricted anteroposterior portions of VLVp that qualitatively appeared to correspond to the frequency representation that was injected in the ICc. Together with the PHA-L tracing, these results suggest that VLVp projects to the lateral shell bilaterally, and that this projection may be topographic for frequency. A few cholera toxin-labeled cells were also seen in the very ventral pole of the contralateral VLVa, a nucleus of the time pathway immediately adjacent to VLVp (Fig. 5); this may be due to the unrestricted injection site in ICc.

One owl received injections of fluorescently labeled latex beads into subdivisions of ICc. Rhodamine- and fluorescein-labeled bcads were injected into the lateral and medial parts of the shell, respectively. Figure 6 shows the restricted injection sites and a schematic of the retrogradely labeled cells that were scored in one section near the anteroposterior middle of VLVp. The data show that the lateral shell receives bilateral input from VLVp. The injection into the medial shell labeled only cells in the contralateral VLVp. No cells in VLVa were labeled by either tracer.

From both the anterograde results with PHA-L (Fig. 2), and 

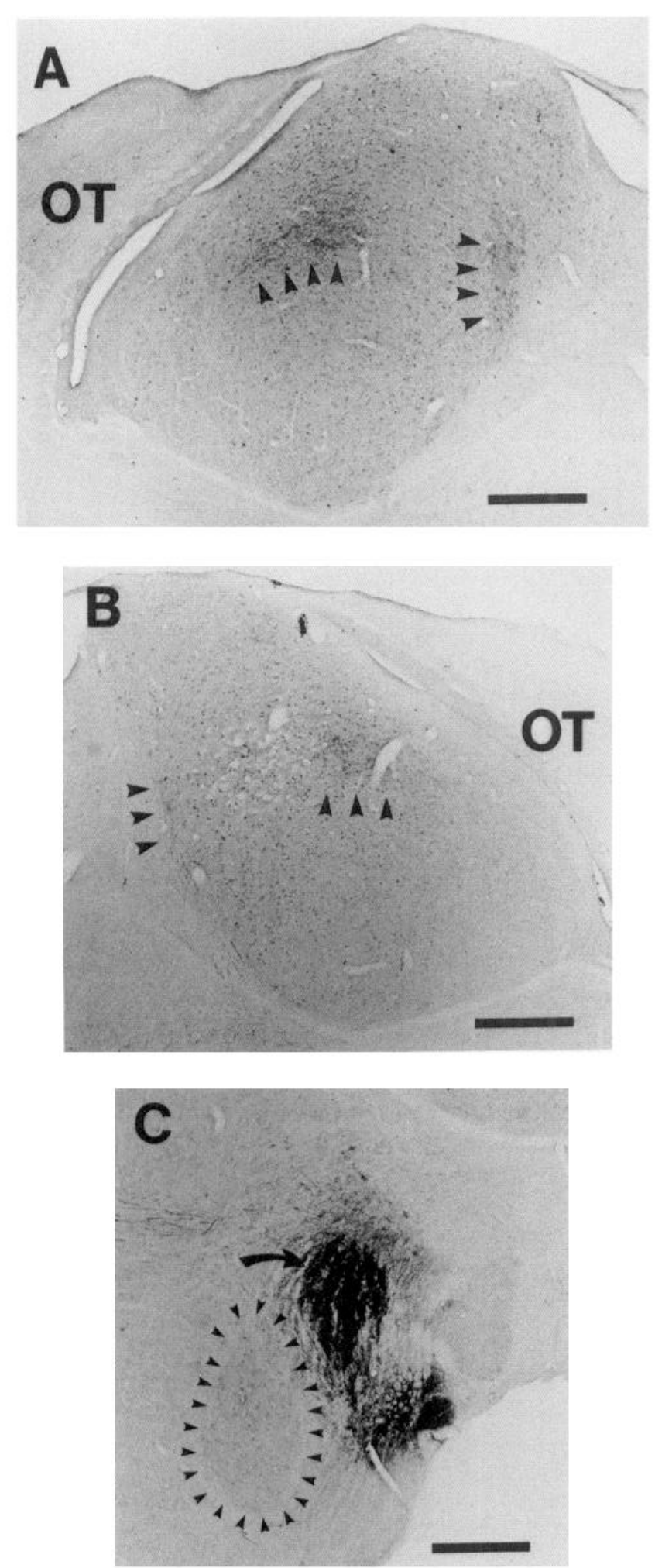

Figure 2. The VLVp projects bilaterally to the inferior colliculus. $A$, Anterograde label (arrowheads) is seen in the contralateral inferior colliculus from an injection of PHA-L into VLVp. The pattern of label in inferior colliculus suggests that the shell of ICc receives terminals from VLVp. Scale bar, $500 \mu \mathrm{m}$. B, Anterograde label (arrowheads) is seen similarly, although more faintly, in the ipsilateral inferior colliculus. Scale bar, $500 \mu \mathrm{m}$. $C$, The injection site of PHA-L in the right VLVp is seen as the darkened region (curved arrow) and does not impinge upon VLVa (arrowheads). Scale bar, $500 \mu \mathrm{m}$. Owl 438.
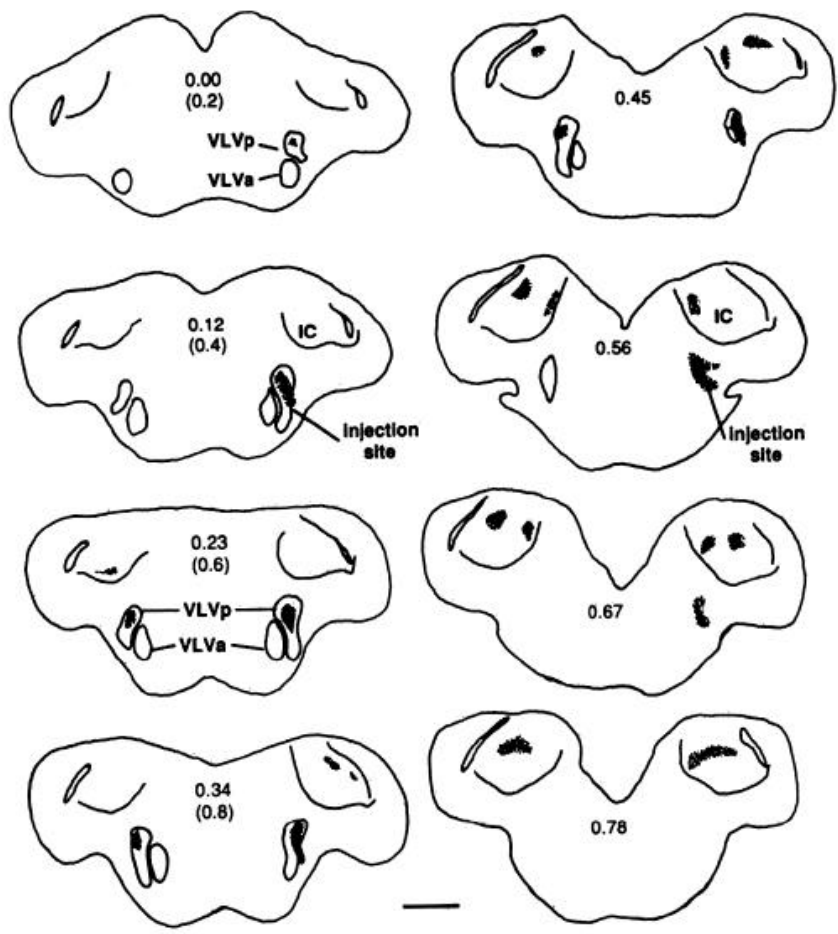

Figure 3. Camera lucida reconstruction for PHA-L injection site and anterograde label for owl 438. The right VLVp was injected; anterogradely labeled terminals are shown in stippling. Numbers indicate normalized distance from the anterior pole of inferior colliculus; numbers in parentheses indicate normalized distance from the anterior pole of VLV for VLVp and VLVa. Scale bar, $1.6 \mathrm{~mm}$.

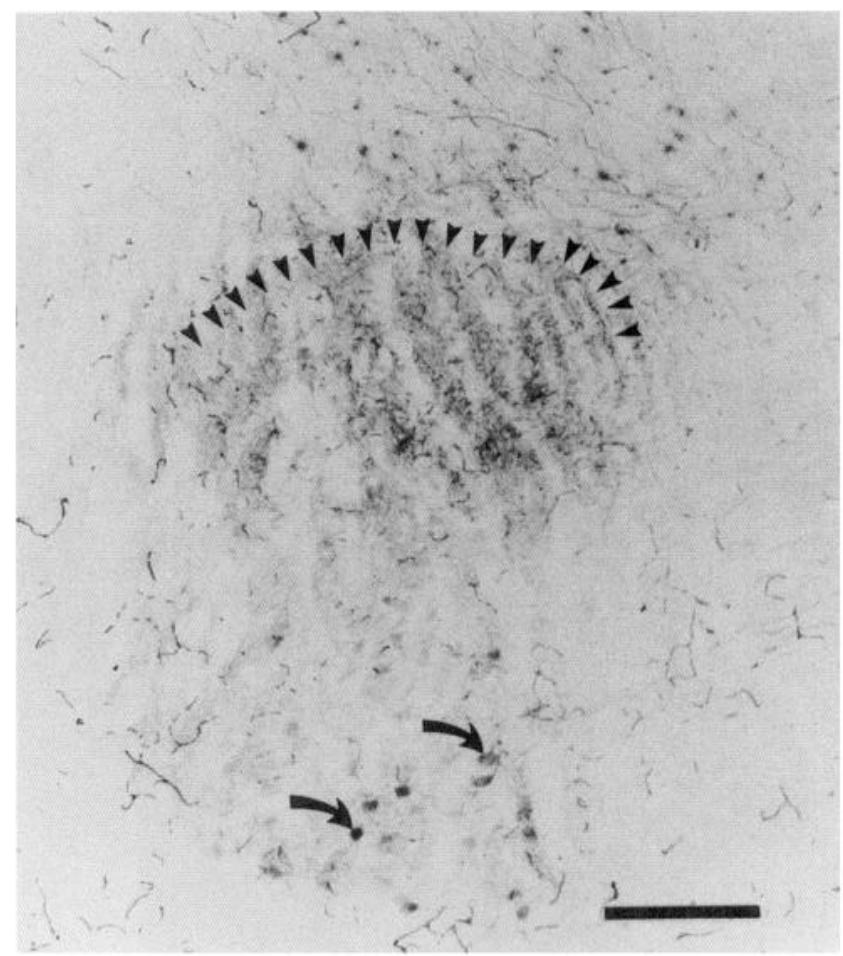

Figure 4. The VLVp on each side are connected reciprocally. From the PHA-L injection into the right VLVp in owl 438, anterograde label was seen in the dorsal region of the left VLVp (arrowheads), whereas retrogradely labeled cell bodies were seen in the ventral left VLVp (curved arrows). Scale bar, $250 \mu \mathrm{m}$. 


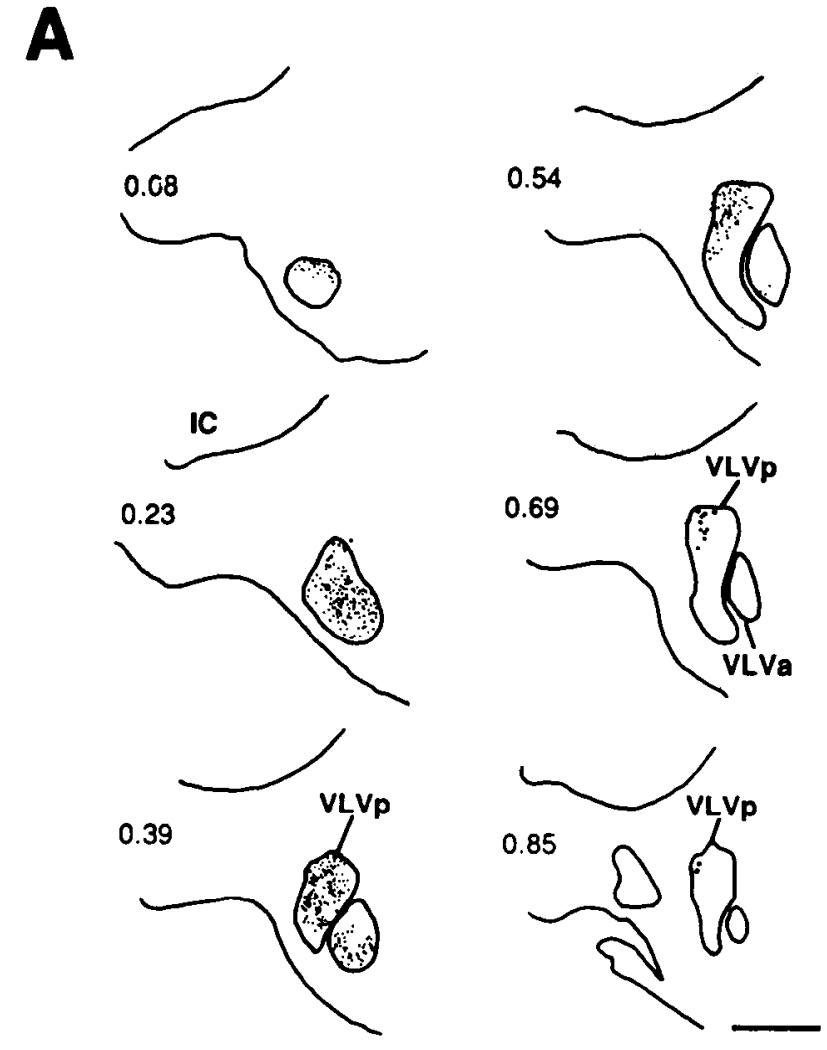

B
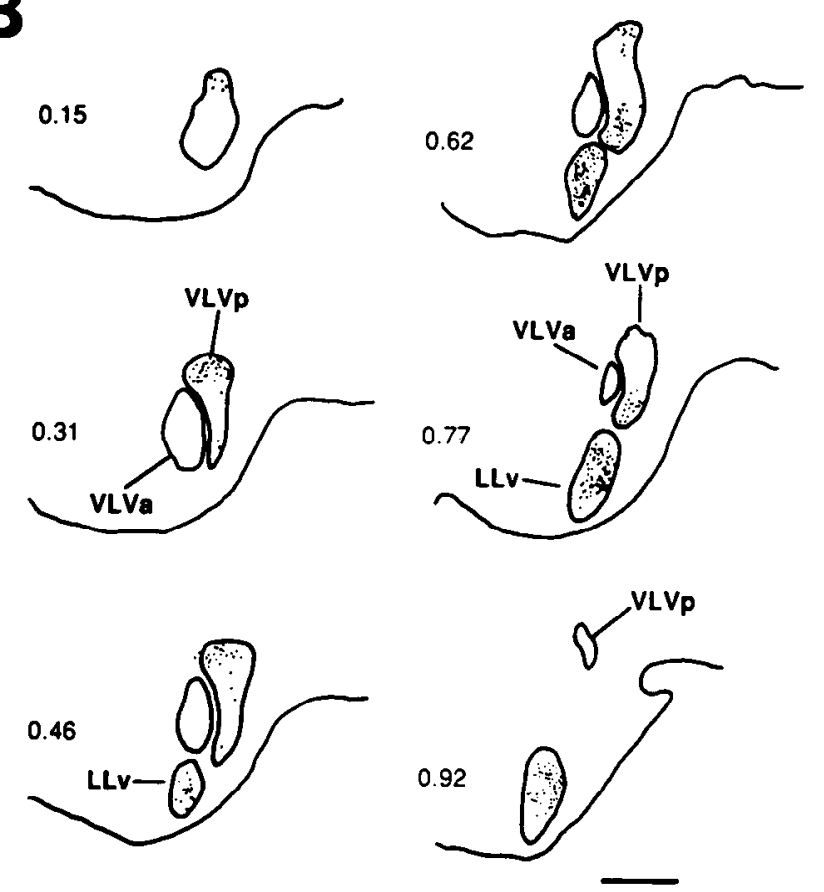

Figure 5. The inferior colliculus receives bilateral input from VLVp. The B-subunit of cholera toxin was pressure injected into the right lateral shell of ICc under physiological guidance. The injection site was, however, not restricted to the lateral shell. This figure shows camera lucida reconstructions of the retrograde label. $A$, Retrogradely labeled cells (dots) were plotted individually in the contralateral VLVp and VLVa. These two nuclei fuse anteriorly. Numbers indicate normalized anteroposterior distance from the anterior pole of VLV. Scale bar, $1.0 \mathrm{~mm}$. $B$, Retrogradely labeled cells in the ipsilateral VLVp, VLVa, and LLv. the retrograde tracing with fluorescent beads (Fig. 6), it appears that medial and lateral parts of the shell receive equally strong projections from the contralateral VLVp, but that the ipsilateral VLVp may project mostly to the lateral shell. I did not find any evidence that the medial and lateral shell are connected; the anterograde targets of the medial shell remain unknown. The present results together with previous findings show that ICX rcceives polysynaptic bilatcral input from VLVp via the lateral shell.

\section{Responses in VLVp \\ $V L V p$ cells are affected by iontophoresis of $G A B A_{A}$ receptor agonists or blockers}

Table 2 lists all owls used in physiological experiments reported here. I first investigated the responses of cells in VLVp to iontophoretically applied $\mathrm{GABA}$, and to the $\mathrm{GABA}_{\mathrm{A}}$ receptor blocker BMI. Figure 7.A shows an increased response to ILD as a function of time during and after (POST) BMI iontophoresis. Of 32 neurons tested in four owls, 25 showed a reversible increase in firing rate with $\mathrm{BMI}$ application; the remaining cells showed no alteration in response properties. Iontophoresis of GABA either had no effect (five cells) or decreased the firing rate of neurons (five cells, four owls; Fig. 7B). In all cases where these drugs had any effect at all, BMI increased the firing rate while GABA decreased it. These effects were seen at all ILDs.

Controls were run by iontophoresing isotonic saline at currents and $\mathrm{pH}$ matched to that of the drugs that were iontophoresed. Survey studies with drugs that affect other inhibitory transmitter systems served as controls as well: no changes in response were seen with applications of the muscarinic cholinergic antagonist atropine (10 cells), the transmitter glycine (2 cells) and its antagonist strychnine (17 cells), or the putative transmitter $\beta$-alanine ( 7 cells).

These results indicate that at least some of the neurons in VLVp have $\mathrm{GABA}_{\mathrm{A}}$ receptors, and that the magnitude of their evoked response can be increased by BMI or decreased by GABA. This finding provided the basis for the experiments below in which these drugs were injected globally into VLVp to modulate the gain of the population response.

An additional drug used was the potent GABA $_{\mathrm{A}}$ agonist muscimol. Iontophoretic application of muscimol to VLVp cells resulted in a complete abolition of spontaneous and evoked firing (data not shown). Furthermore, this effect was irreversible on the time scale of an hour. Given that the two VLVps are reciprocally connected (Fig. 4; Takahashi and Keller, 1992), muscimol was used next to determine the functional connection between the two VLVps.

\section{Mutual inhibition of $V L V p$}

Muscimol was pressure injected into the VLVp on one side, while recording the response to interaural level differences in the VLVp on the opposite side. Figure 8 shows the response curve of a single neuron in the VLVp opposite to the injected side. Initially, the neuron is excited by sound at the contralateral ear, and inhibited strongly as sound level at the ipsilateral ear is increased; this response is typical of neurons in the dorsal

No labeled cells were seen in the ipsilateral VLVa. Numbers indicate normalized anteroposterior distance from the anterior pole of VLV. Scale bar, $1.0 \mathrm{~mm}$. Owl 438. 

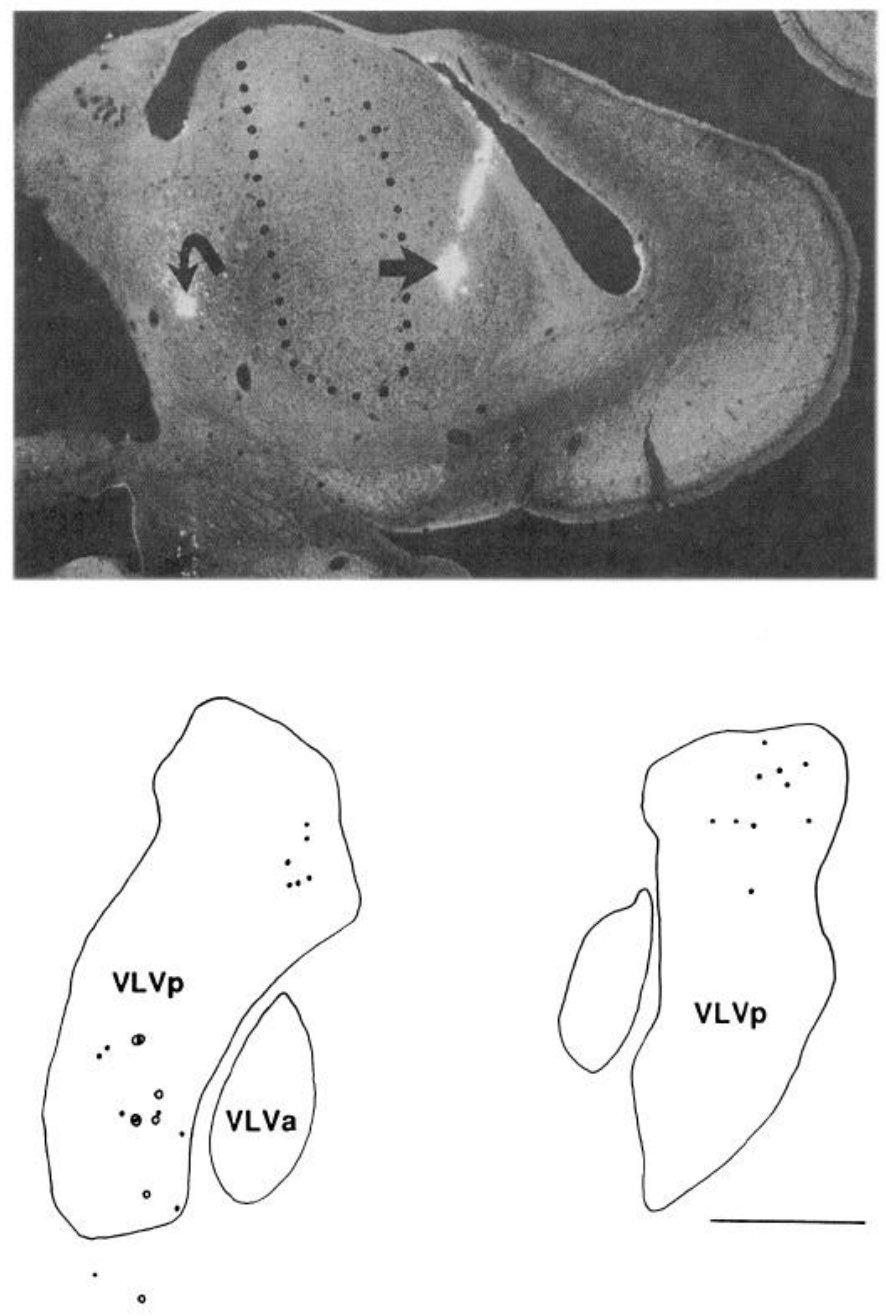

Figure 6. The medial and lateral parts of the shell both receive inputs from VLVp. Top, Fluorescein-labeled latex beads were injected into the medial shell (curved arrow) and rhodamine-labeled beads were injected into the lateral shell on the same side (straight arrow). This epifluorescence photomicrograph shows the two injection sites in the right inferior colliculus. Core (dotted line) and shell of ICc were histologically discriminated with AChE staining (Adolphs, 1991, 1993). Bottom, Retrogradely labeled cells were scored under epifluorescent illumination using a $60 \times$ objective with oil immersion. Positions of cells were digitized using a motorized stage and custom software. The two sections through the anteroposterior middle of VLVp show retrogradely labeled cells in both the left (left) and right (right) VLVp. Dots denote rhodamine-labeled cells; circles, fluorescein-labeled cells. The left VLVp section has two cells that are double labeled. Scale bar, $1.0 \mathrm{~mm}$. Owl 391.

regions of VLVp (Manley et al., 1988). Takahashi and Keller (1992) injected the local anesthetic lidocaine into one VLVp and found that inhibition in the opposite VLVp was blocked; their experiment, however, leaves open the possibility that the lidocaine also affected fibers of passage that course through the injection site. I repeated Takahashi and Keller's (1992) experiment with muscimol, which will affect only cell bodies. After injecting muscimol into the opposite VLVp, the neuron is excited uniformly at all ILD, irrespective of the level of sounds at the ipsilateral ear (Fig. 8). The population response in the injected VLVp, recorded through the injection syringe, showed that all activity was abolished in the nucleus when muscimol was injected. Again, these effects were irreversible on the time scale of an hour, probably due to the potency of muscimol at
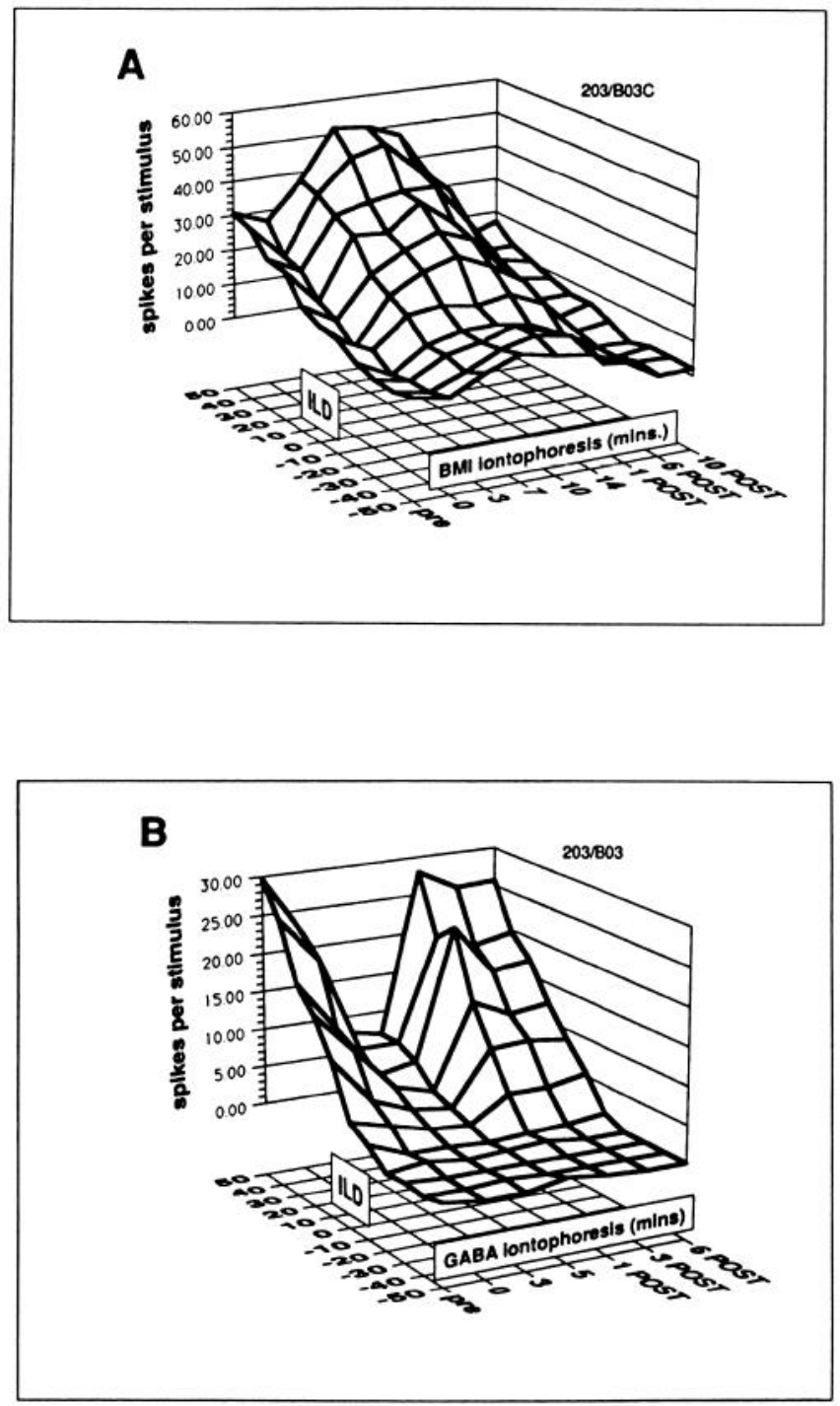

Figure 7. Responses of cells in the VLVp to BMI or GABA. These surface graphs plot ILD versus response versus time. The $x, y$-plane plots ILD in AB SPL (with negative values denoting ipsilaterally louder and positive values denoting contralaterally louder ILDs) versus minutes of drug iontophoresis. The $z$-axis measures mean spikes recorded from the cell per $100 \mathrm{msec}$ of stimulus presentation of white noise. Each intersection in the surface grid represents a data point. Initial time values are minutes of continuous iontophoresis of drug; times marked POST measure time after cessation of iontophoresis. $A$, Response to BMI. Spontaneous rate throughout, 7 spikes per stimulus. $B$, Response to GABA. Spontaneous rate throughout, 7 spikes per stimulus.

the $\mathrm{GABA}_{\mathrm{A}}$ receptor. These results, together with those of Takahashi and Keller (1992), unambiguously identify the contralateral VLVp as the source of inhibitory input to cells in VLVp.

How responses tuned to ILD in the inferior colliculus are generated

\section{Responses of cells in the lateral shell are shaped by GABAergic} mechanisms

The responses of cells in the subdivisions of the inferior colliculus have been studied extensively by several investigators (Knudsen and Konishi, 1978; Takahashi and Konishi, 1986; Adolphs, 1988; Fujita and Konishi, 1989; Takahashi et al., 1989; Mori et al., 1990). I here concern myself only with the responses of cells in the lateral shell of ICc, and in the immediately adjacent 


\begin{tabular}{|c|c|}
\hline $\begin{array}{l}\text { Owl } \\
\text { number }\end{array}$ & Experiments \\
\hline \multicolumn{2}{|l|}{195} \\
\hline \multicolumn{2}{|l|}{203} \\
\hline 299 & Iontophoresis in lateral \\
\hline 391 & shell \\
\hline \multicolumn{2}{|l|}{203} \\
\hline \multicolumn{2}{|l|}{386} \\
\hline 715 & Iontophoresis in VLVp: \\
\hline 391 & RMI \\
\hline \multicolumn{2}{|l|}{715} \\
\hline \multicolumn{2}{|l|}{203} \\
\hline \multicolumn{2}{|l|}{386} \\
\hline 391 & GABA \\
\hline 357 & Muscimol \\
\hline 429 & $\begin{array}{l}\text { Inject muscimol VLVp; } \\
\text { record contra VLVp }\end{array}$ \\
\hline \multicolumn{2}{|l|}{203} \\
\hline 300 & Inject VLVp; record contra \\
\hline 398 & ICx: lidocaine \\
\hline \multicolumn{2}{|l|}{203} \\
\hline 357 & BMI \\
\hline 424 & GABA \\
\hline 357 & Muscimol \\
\hline 195 & Inject VLVp; record ipsi \\
\hline 299 & ICx: lidocaine \\
\hline 299 & BMI \\
\hline \multicolumn{2}{|l|}{299} \\
\hline 424 & GABA \\
\hline 424 & Inject VLVp bilaterally; \\
\hline 451 & record ICx \\
\hline
\end{tabular}

ICx. In the experiments below, cells in subdivisions of IC were identified both by their physiological response properties and by subsequent histological verification of small electrolytic lesions left at the recording site. This allowed unambiguous assignment of cells to either the lateral shell or to ICx. Cells in ICx show sharp tuning to ILD, consistent with their role in representing spatially restricted sounds, while neurons in the lateral shell show more heterogeneous responses to ILD. Furthermore, cells in the lateral shell are sharply tuned to frequency, and do not exhibit side-peak suppression of ITD responses to noise; cells in ICx are very broadly tuned to frequency and show side-peak suppression of ITD responses to noise. All of these response criteria were used in assigning cells to the lateral shell or to ICX.

What shapes the responses to ILD in the lateral shell? Investigation of this question should shed light on the synthesis of responses in ICx, to which the lateral shell provides auditory input. Figure 9 shows that some of the inhibition of response seen in the lateral shell is GABAergic. All lateral shell cells are inhibited by sounds that are loud at the ipsilateral ear, and some cells in the lateral shell are also strongly inhibited at contralaterally loud ILDs. Inhibition by sounds loud at one or at both ears

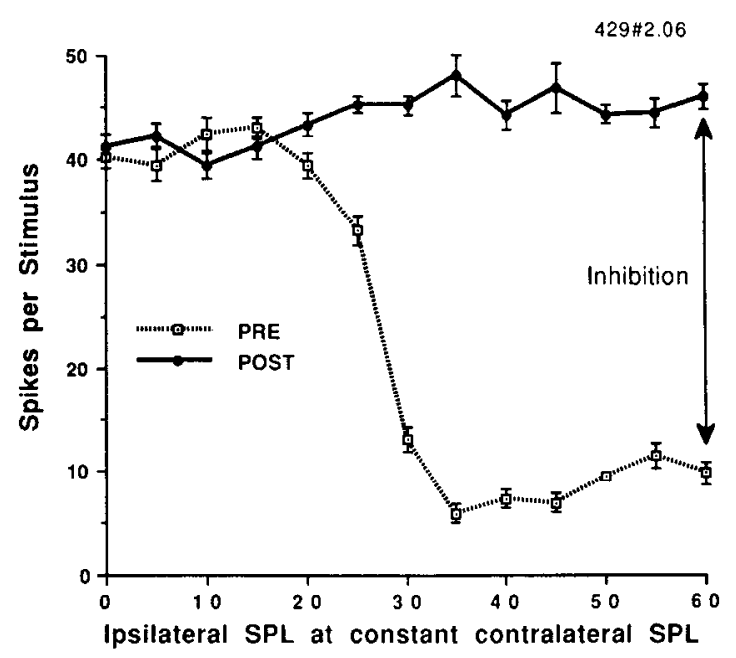

Figure 8. The VLVp provide reciprocal inhibition to each other. Response of a neuron in VLVp to ILD of a $5.0 \mathrm{kHz}$ tone. The sound pressure at the contralateral ear was held constant at $40 \mathrm{~dB}$ while the ipsilateral sound level was increased from 0 to $60 \mathrm{~dB}$ SPL along the abscissa (corresponding to an ILD range from 40 to -20 ). The ordinate plots mean spikes per stimulus presentation before (PRE) and after (POST) injecting muscimol into the VLVp on the side opposite from the VLVp that was being recorded. The muscimol injection caused an irreversible block of inhibition by sounds loud at the ipsilateral ear, but left the amount of excitation supplied by the contralateral ear unaffected. Spontaneous rate throughout, 5 spikes per stimulus.

can be blocked with BMI (Fig. 9). There are several, distinct effects seen with BMI iontophoresis in Figure 9. In all cases, and at all values of ILD, responses increase after BMI application. Additionally, the shape of the response curves and the binaural interactions it may reflect are altered with BMI. These results suggest that BMI both blocks tonic GABAergic inhibition and blocks inhibition that contributes to shaping the cell's binaural response profile. The detailed role GABAergic mechanisms play in shaping responses in the lateral shell, however, is not addressed by these studies since it is not known which inputs to a cell BMI iontophoresis might affect. In some cases in which BMI iontophoresis resulted in monotonic response curves (e.g., Fig. $9 B$ ), very prolonged application eventually resulted in nonmonotonic responses (e.g., Fig. 9D). This may reflect the differential access of iontophoresed BMI to spatially segregated inputs distal to the recording site; this point is considered in more detail in Discussion.

Of 22 cells recorded in the lateral shell of four owls, 20 cells showed a clear effect of block of inhibition by BMI iontophoresis, and their binaural response profiles were dramatically changed in all cases. These results show that lateral shell cells receive a $G A B A$ ergic input that provides strong inhibition at one or both extremes of the ILD range, and that such GABAergic inhibition importantly shapes the responses to binaural stimuli.

Which structures might provide this inhibitory input to the lateral shell? Based on the hodology shown above, VLVp is a candidate for providing at least some of this input. I addressed this question by injecting drugs globally into VLVp while recording responses to ILD in the inferior colliculus.

\section{Some lateral shell neurons receive GABAergic inhibition from $V L V p$}

Figure $10 \mathrm{~A}$ shows an experiment in which BMI was injected into VLVp to potentiate activity within that nucleus, and the 
A
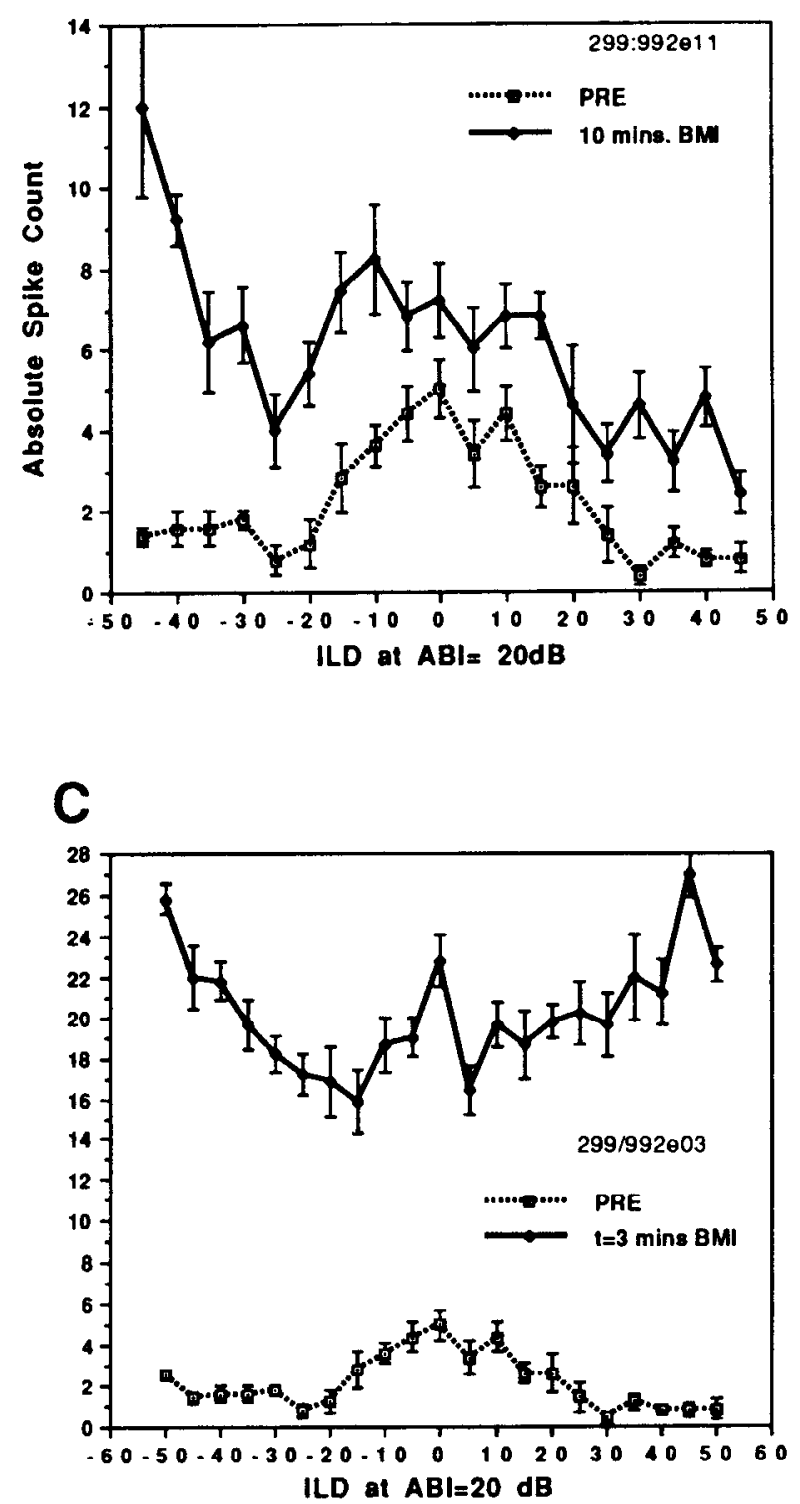

B

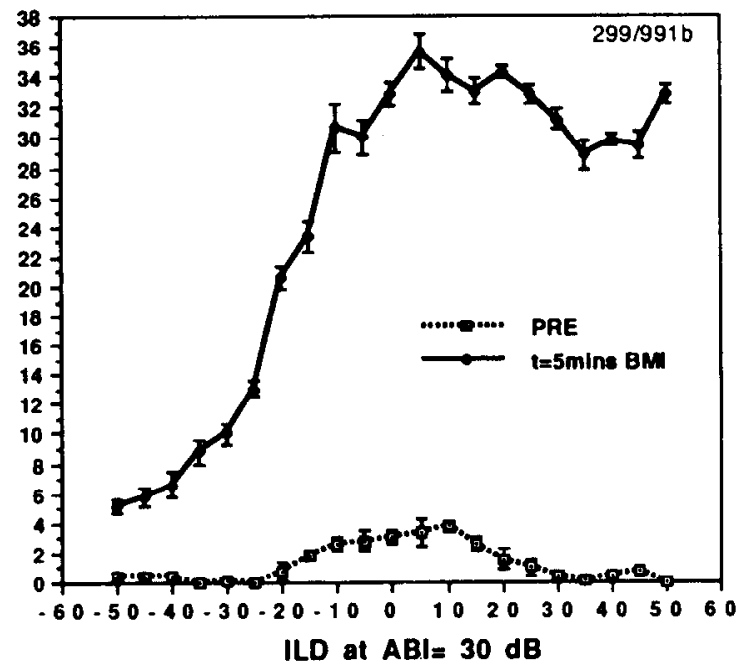

D

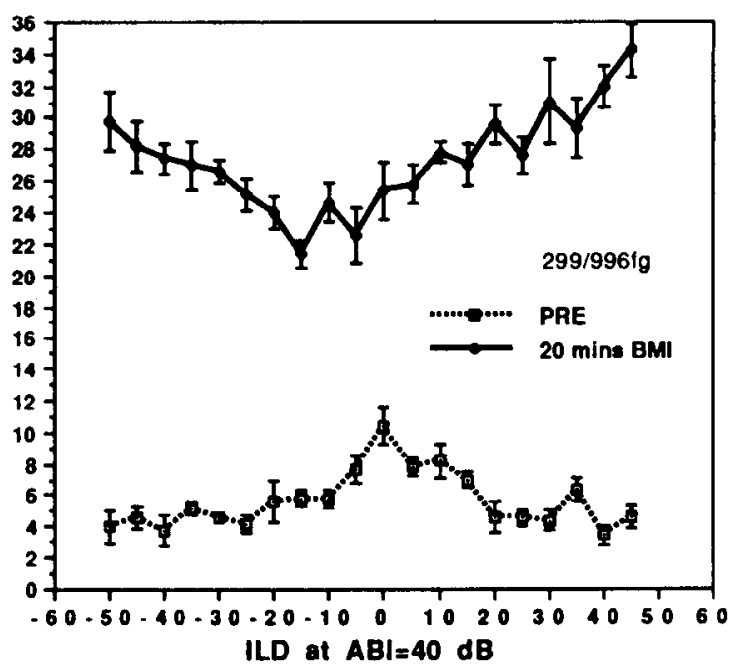

Figure 9. GABAergic inhibition shapes responses in the lateral shell. The response to ILD of single cells in the lateral shell of ICc was recorded before and after iontophoresis of BMI. $A$, Some cells showed a marked increase in response especially at ipsilateral ILDs. Spontaneous rate throughout, 0.0 spikes per stimulus. $B$. Some cells showed an increase in response especially at contralateral ILD. Spontaneous rate throughout, 1.0 spike per stimulus. $C$ and $D$, Most cells showed increases in their firing rates at all ILDs, and a marked response at extreme ILD values where they were previously strongly inhibited. Spontaneous rate throughout for $C, 0.0$ spikes per stimulus. Spontaneous rates for $D: P R E$, 1.0 spike per stimulus; after 20 min BMI, 6.0 spikes per stimulus. Stimulus was pseudorandom white noise in all cases.

response of a neuron in the contralateral lateral shell of ICc was recorded. The stimulus consisted in a constant level of sound at the contralateral ear, which excited this lateral shell neuron, while varying the sound level at the ipsilateral ear. This stimulus was the same as used previously in Figure 8, where the inhibition between the two VLVps was investigated. At loud ipsilateral sound levels, the lateral shell neuron is inhibited below the tonic activity due to the contralateral sound (Fig. 10A, PRE). Upon injection of BMI into the contralateral VLVp, this inhibition became much stronger (Fig. 10A). Increasing the gain of the response in VLVp globally thus causes increased inhibition of lateral shell neurons at those ILDs where activity in VLVp is greatest.

An additional experiment to confirm that VLVp provides inhibition to the IC is shown in Figure $10 B$. The paradigm was the same as for Figure 10A: a constant level of excitation was provided to a lateral shell neuron by a fixed sound level in the contralateral ear. This cell had a nonmonotonic response to varying ipsilateral levels; its response to ILD at fixed ABI (not shown) showed a symmetrical peak. As the sound in the ipsilateral ear is made very loud, it inhibits the cell (PRE), and injection of muscimol into the contralateral VLVp abolishes this inhibition that the VLVp normally provides. There is no change at large contralateral ILD (Fig. 10B), since the injected (contralateral) VLVp does not provide inhibition (its cells do not respond) at those ILDs. The effects shown in Figure $10 B$ were irreversible with muscimol, probably due to the potency of the drug at the $\mathrm{GABA}_{\mathrm{A}}$ receptor. The results from this ex- 


\section{A. BMI}

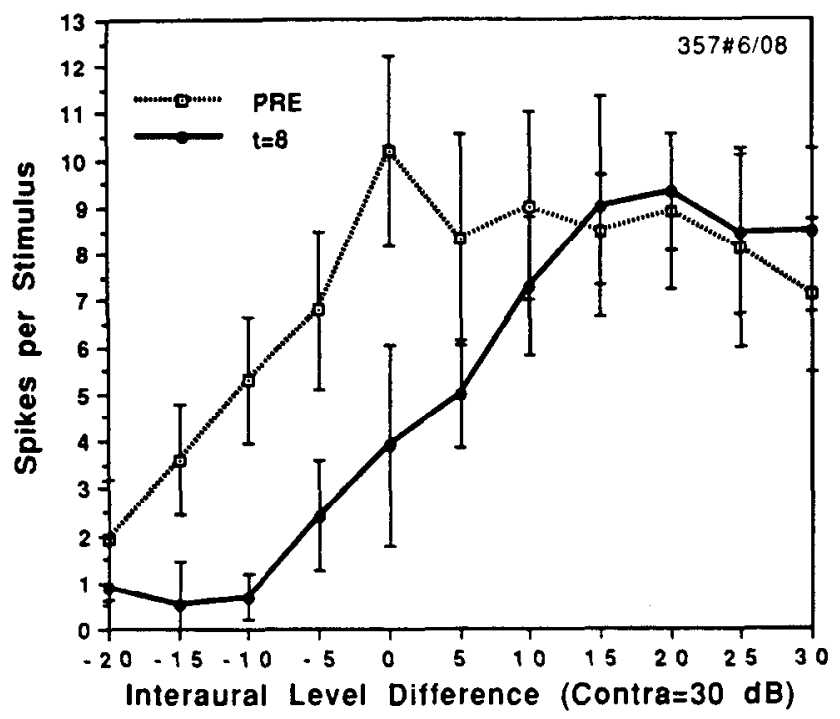

\section{B. Muscimol}

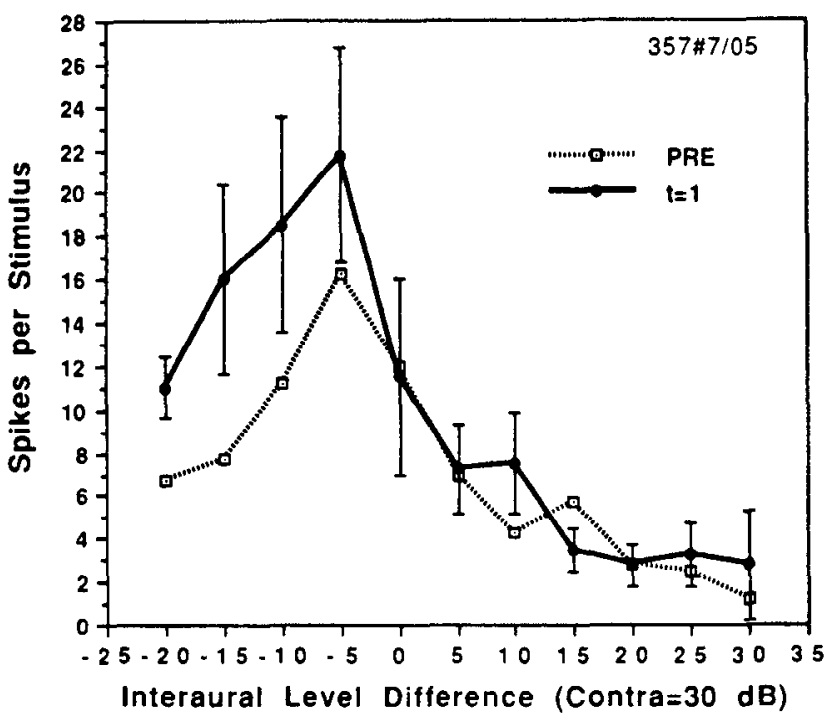

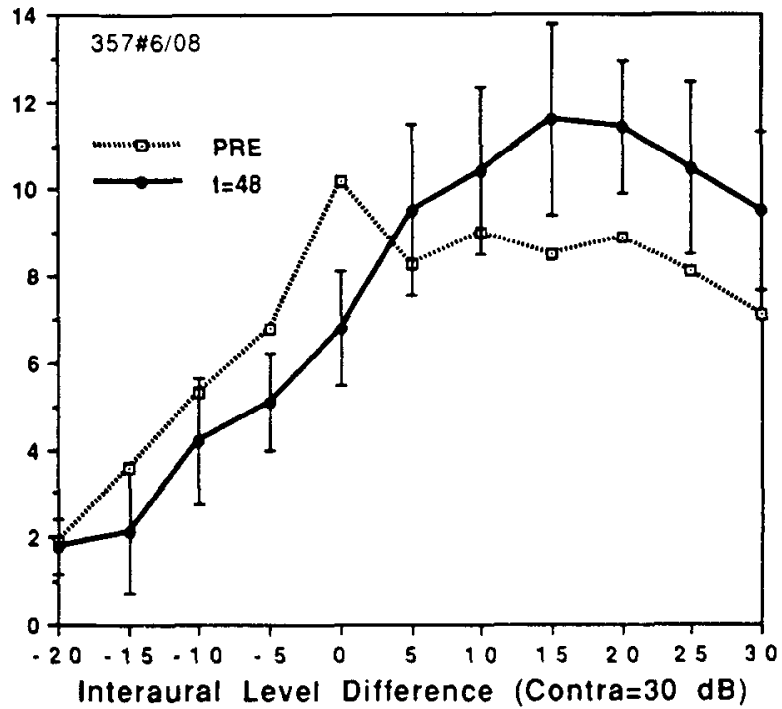

Interaural Level Difference (Contra=30 dB)

Figure 10. The contralateral VLVp provides inhibition to the lateral shell. A:Left, Response of a lateral shell cell to a sound at constant contralateral level $(30 \mathrm{~dB})$ while varying the ipsilateral level. The ipsilateral level is $50 \mathrm{~dB}$ at the origin, and decreases to 0 at the far right of the abscissa. Note that the ILD plotted on the $\mathrm{x}$-axis, unlike in similar plots, is not at constant ABI in this case. Responses are shown before (PRE) and 8 min after injecting $0.2 \mu \mathrm{l} \mathrm{BMI}$ into the contralateral VLVp. There is significantly more inhibition by ipsilateral sounds after BMI injection. Right, The effect recovers after $48 \mathrm{~min}$. Stimulus was pseudorandom white noise. Spontaneous rate throughout, 1.5 spikes per stimulus. $B$, Response of a lateral shell cell to same stimulus as in $A$; this cell has a nonmonotonic response to changing ipsilateral levels. Left, After injecting $0.2 \mu l$ of muscimol, there is a small decrease in the strength of inhibition by ipsilateral sounds $(t=I)$, the reverse of the effect seen above with BMI. Right, This effect increases and has not recovered at $71 \mathrm{~min}$. Stimulus was pseudorandom white noise. Spontaneous rate throughout, 0.0 spikes per stimulus.

periment are very similar to those of Figure 8, where muscimol was injected into VLVp to decrease the inhibition it supplied to the VLVp on the opposite side. These experiments do not address the issue of whether the same cells in one VLVp may inhibit both the contralateral lateral shell and the contralateral VLVp. Whenever drugs were pressure injected into VLVp (here and in experiments below), the response of a population of neurons in VLVp near the injection site could be recorded through the syringe with which the drugs were injected. The population responses thus recorded corroborated the results from iontophoresis reported above.

Given the iontophoretic results that BMI can block inhibition locally in the lateral shell (Fig. 9), one might expect the inhibition that VLVp provides to the colliculus (Fig. 10) to be GABAergic. To test this, I injected a very large amount of BMI into the contralateral VLVp while recording from a lateral shell cell. The 
amount injected was more than twice the volume of BMI that was injected in the experiment of Figure 10; after such a massive injection, recording through the injection syringe showed that neurons in VLVp had a high firing rate independent of the auditory stimulus. Cells in VLVp could now provide inhibition at ILDs where they do not normally do so. A very strong increase in inhibition was seen in the lateral shell at all ILD values (Fig. $11 A$ ), since VLVp had a high firing rate across the whole ILD range. Now, BMI was additionally applied iontophoretically to the lateral shell cell from which I was recording. Figure 11 shows that BMI iontophoresis onto the lateral shell neuron can partially block the inhibition induced by increasing the activity of the contralateral VLVp. The effect of the iontophoresis was reversible, as was, with a longer time course, the effect of the VLVp injection. Two such experiments (in one owl) gave identical results. The experiments of Figures 9-11 suggest that there are neurons in the lateral shell of $\mathrm{ICc}$ that receive direct, GABAergic inhibition from VLVp.

Manipulating responses in one VLV affects responses in ICX

The response in VLVp affects responses in the contralateral ICX. The above experiments show that VLVp provides inhibition to at least some cells in the lateral shell of $\mathrm{ICc}$. The responses to ILD in the lateral shell are very heterogeneous, and no map of ILD has been found there. I chose next to examine the ICx, which contains only neurons that are very sharply tuned to ILD and that map sound source elevation. Since the lateral shell provides all of the auditory input to the ICx, one might expect that the inhibitory inputs from VLVp would also be reflected in the responses of ICX neurons. The uniformity of responses to ILD in the ICx makes this apex of the processing hierarchy a clearer locus at which to analyze the functional contribution of VLVp.

VLVp was injected with three separate drugs: lidocaine, GABA, or BMI. In each case, the drug was pressured injected into the nucleus while recording from a single cell in the contralateral ICx. Responses recorded through the injection syringe in VLVp showed a marked attenuation or abolition of activity in that nucleus with lidocaine and GABA, and an increase in activity with BMI. The population responses were qualitatively similar to the responses obtained with previous iontophoresis (Fig. 7). Figures 12 and 13 show the responses to ILD of cells in the ICX before and after injection of lidocaine or GABA into the contralateral VLVp. With both drugs, the change in response of the IC $x$ cell was consistent with a decreased inhibition by sounds loud at the ipsilateral ear. However, the effect with lidocaine could also be interpreted as a shift of the pcak rcsponsc to morc ipsilateral values; this is considered in more detail in Discussion. The time course of the effect was of shortest duration with GABA (about $10 \mathrm{~min}$ ). The effect with lidocaine lasted about 15-20 min, in agreement with the time courses seen in Takahashi's experiments (Takahashi et al., 1984; Takahashi and Keller, 1992).

What happens when the response in VLVp is potentiated instead of attenuated? Figure 14 shows the result from a cell in ICx before and after injecting BMI globally into the contralateral VLVp. The effect on the response function of the ICx neuron was qualitatively the converse of that seen with the injections of the inhibitors of neural activity presented above. The inhibition by sounds loud at the contralateral ear was diminished this time. Only relatively small injections of BMI had this effect; massive injections $(>0.5 \mu \mathrm{l})$ resulted in an attenuation of re- sponse in ICx at all values of ILD, similar to the effect seen in the lateral shell in Figure 11 (data not shown for ICx). The ICx neuron's selectivity for ITD was also recorded during all these experiments, and remained invariant (Figs. 12-14).

The response in VLVP affects responses in the ipsilateral ICX. All of the above experiments of recording in the colliculus while injecting the contralateral VLVp probably cause at least some of their effects via the ipsilateral VLVp, since the two VLVps are commissurally connected. A more direct test of the involvement of the ipsilateral VLVp is to inject it directly while recording from ICx. Figure 15 shows the results of such an experiment. GABA was injected globally into the VLVp, and the response to ILD was recorded in the ICX on the same side. This injection attenuated the activity of cells in VLVp, as recorded through the injection syringe. In the ICx, a complete abolition of inhibition by contralaterally loud sounds was seen. The time course for these effects was similar to the results from injecting the contralateral VLVp. Lidocaine could not be used for the experiments in the ipsilateral VLVp, because it also blocks action potentials in axonal fibers of passage. When lidocaine is injected into the ipsilateral VLVp, fibers of the lateral lemniscus providing input to the inferior colliculus on the same side are affected; the result is an abolition of all evoked neural activity in the ICx (data not shown).

Summary: VLVp can affect cells in the colliculus on either side of the brain. Results from experiments in which VLVp was injected and responses to ILD were recorded from ICx are summarized in Figure 16. When the contralateral VLVp was injected with GABA or lidocaine, 1 observed a decrease of inhibition at sounds ipsilaterally loud in the ICx. One measurement of such a decrease of inhibition is the shift of the center-of-mass of the region under the response curve of the ICx neuron. A decrease in inhibition by ipsilaterally loud sounds will shift the center-of-mass of the response to ipsilaterally loud ILD. Figure 16 shows the average shifts in the center-of-mass of the response curve recorded in the ICx upon injection of the contralateral VLVp with GABA $(n=4)$ or lidocaine $(n=11)$. Together with a decrease in inhibition by sounds loud at the ipsilateral ear, the center-of-mass can also be shifted in the same direction by an increase of inhibition by sounds loud at the contralateral ear. This latter effect was sometimes observed as well, although its magnitude depended on how completely inhibited the response at contralaterally loud ILD was in the first place.

The center-of-mass of the ILD-response curve in the ICX shifts in opposite directions with the injections of lidocaine or GABA on the one hand, and with BMI $(n=7)$ on the other (Fig. 16). These shifts were statistically significantly different between lidocaine and BMI $(p=0.0005$, two-tailed MannWhitney $U$ test), and between GABA and BMI $(p=0.0082)$.

The results from seven experiments in which the ipsilateral VLVp was injected with GABA are also summarized in Figure 16; the response curve shift obtained when GABA was injected into the ipsilateral VLVp was in the opposite direction and differed significantly from the curve shift with GABA injected into the contralateral VLVp $(p=0.0082$, Mann-Whitney $U$ test).

Inhibition from $V L V p$ renders cells in ICX binaurally exclusive. One model, which is presented in more detail in Discussion, is that cells in the inferior colliculus receive excitation that is not tuned to ILD. This excitation would lead to a response also for monaural stimuli, as is seen in all nuclei below the level of ICx. One of the defining features of cells in the ICx (and also 

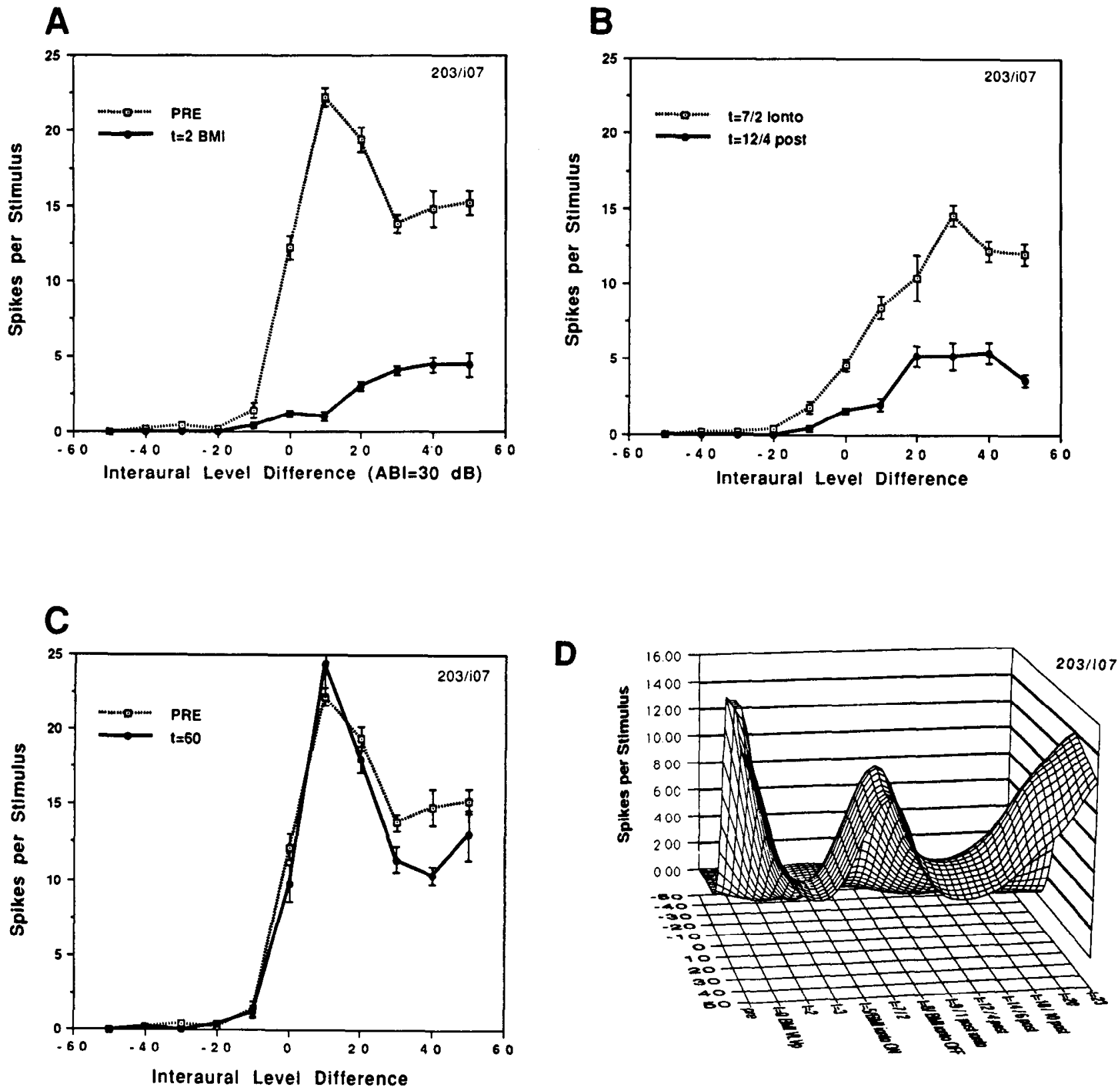

Figure 11. The contralateral VLVp provides GABAergic inhibition to the lateral shell. A very large (0.5 $\mu$ l) injection of BMI was made in VLVp while recording from a neuron in the contralateral lateral shell. After the response of the lateral shell neuron had been nearly completely inhibited by this massive injection, BMI was applied iontophoretically to the lateral shell neuron to see if the inhibition could be locally blocked. $A$, Response of a neuron in the lateral shell to ILD before and 2 min after injecting BMI into the contralateral VLVp. $B$, Response 7 min after the injection into VLVp, and 2 min after beginning continuous iontophoresis of BMI onto the lateral shell neuron $(t=7 / 2$ ionto). The inhibition due to the VLVp injection is attenuated. Twelve min after the initial VLVp injection and $4 \mathrm{~min}$ after terminating the BMI iontophorcsis $(t=12 / 4$ post $)$, the effect of the iontophoresis has recovered, but the effect of the VLVp injection is still present and the cell is strongly inhibited again, as in $A$. $C$, After 1 hr, the response of the lateral shell neuron has recovered to the preinjection case as the effect of the BMI injected into the VLVp has worn off. $D$, Surface plot of the same experiment with time along the $x$-axis. The prominent peak in the middle shows the block of induced inhibition by BMI iontophoresis. The surface was smoothed with a fourth-order spline. Stimulus was pseudorandom white noise. Spontaneous rate throughout, 0.0 spikes per stimulus.

of some cells in the lateral shell), however, is that they are binaurally exclusive: cells in ICx are tuned to a particular ILD and will be inhibited by monaural stimuli. VLVp may provide such inhibition. Figure 17 summarizes the results from several experiments in which VLVp was injected and responses were recorded in $\mathrm{ICx}$, similar to the summary shown previously in Figure 16. The ordinate plots the change in the response to monaural stimuli recorded in the ICX when VLVp is injected. When activity in VLVp is reduced, there is a larger response in
ICx to monaural stimuli. Ipsilaterally loud sounds can inhibit ICx cells via the contralateral VLVp, while the VLVp ipsilateral to the ICx mediates the inhibition due to sounds that are loud at the contralateral ear (Fig. 17, hatched vs. solid bars). These data support the idea that VLVp provides inhibition at monaural stimuli, with the VLVp on each side inhibiting responses that are loud at one ear. For sounds of small ILD (loud at both ears), neither VLVp inhibits the response and a window is provided through which the non-tuned excitation can drive the ICx 


\section{Lidocaine}
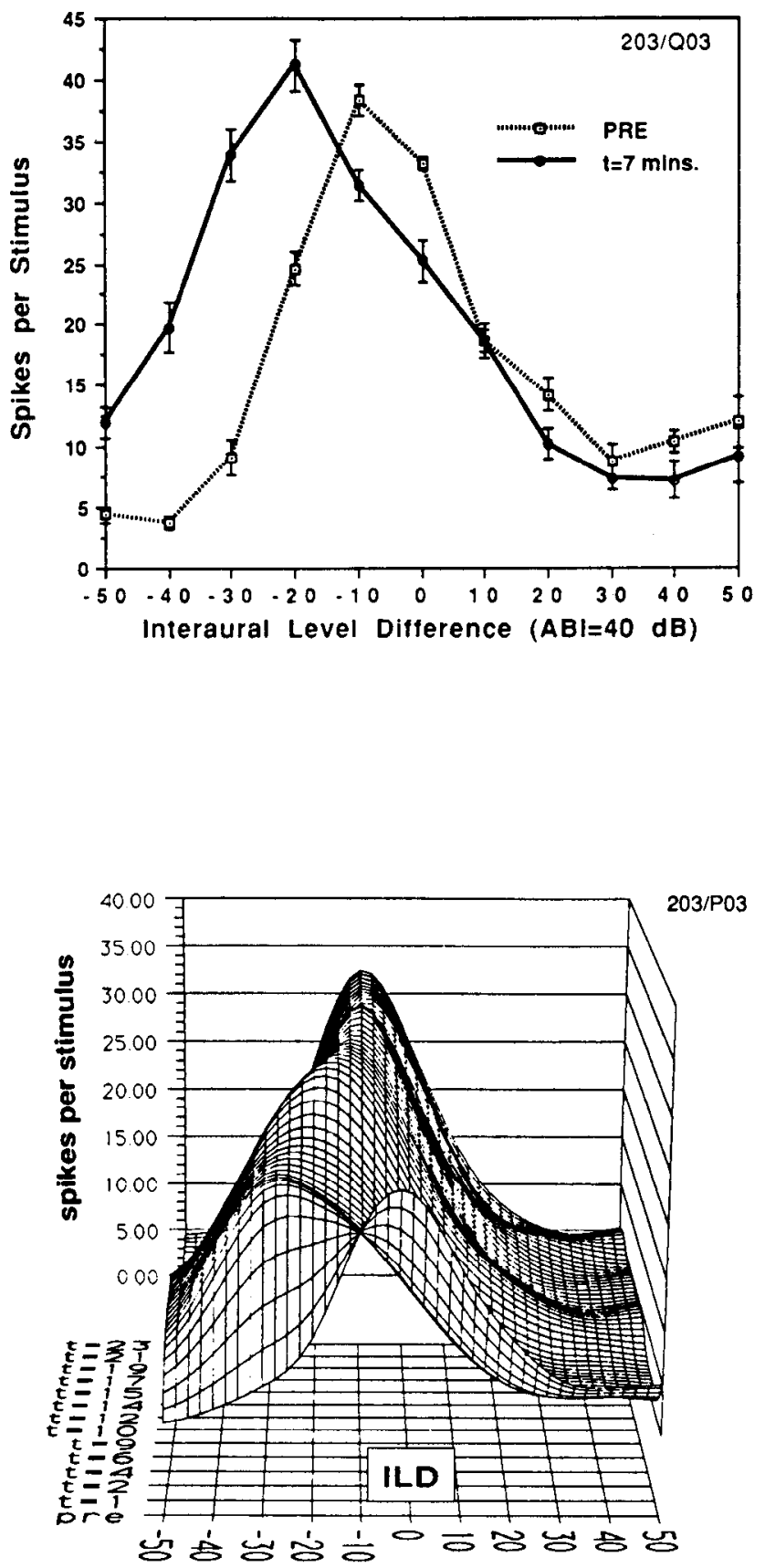
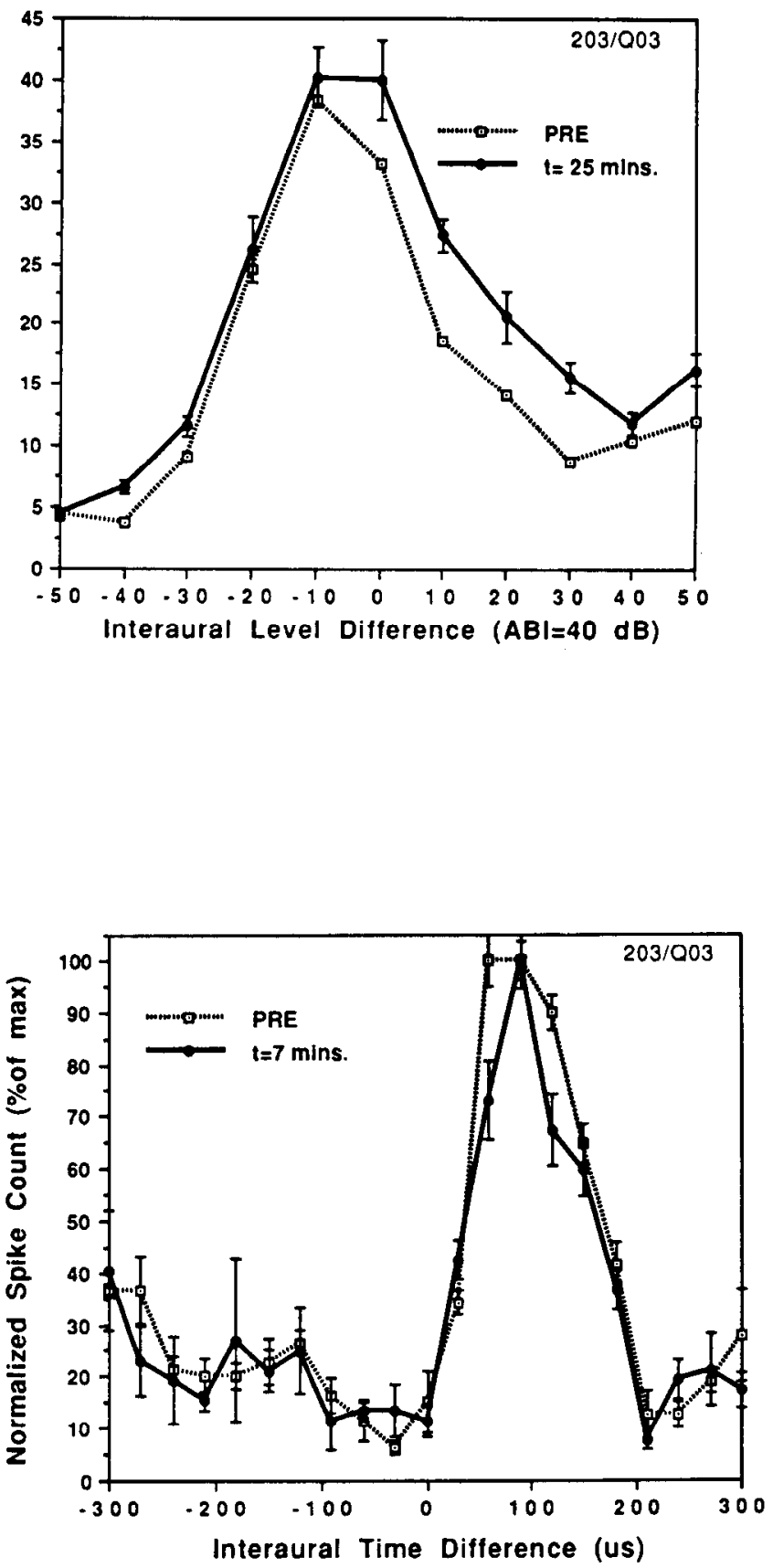

Figure 12. Injecting lidocaine into the contralateral VLVp affects responses in the ICx. Lidocaine was injected into one VLVp and the response of a single neuron in the contralateral ICx was recorded to ILD. Upper left, Responses to ILD before (PRE) and 7 min after injecting the lidocaine $(\ell=7$ mins. $)$ are shown: there is an increase in the response at large ipsilateral ILD, logether with a shift of the peak response. Upper right, The response recovers to the preinjection case after $25 \mathrm{~min}$. Lower left. A surface plot showing the temporal evolution of this effect for the same experiment. The surface was smoothed with a cubic spline for better visualization. Lower right, Response of the neuron to ITD during the experiment was invariant. ITD was presented at the optimal ILD of the cell prior to injection. Stimulus was pseudorandom white noise in all cases. Spontaneous rate throughout, 1.0 spike per stimulus.

cell. Since the input from VLVp to ICx is polysynaptic, the above interpretations can only be made at the functional level; the sign of the inputs that ICx receives directly from the lateral shell is not known.

Bilateral injection of VLVp affects the ICX. All the above experiments, in which one VLVp was injected with a drug, are in part confounded by the commissural connection between the
VLVp on each side of the brain. Changing the response in one VLVp will also change the response in the VLVp on the opposite side (in the opposite direction). This makes an analysis of the effect of each VLVp on the responses in ICx difficult.

To attempt to eliminate this confounding factor, I carried out a final set of experiments in which VLVp was bilaterally injected with GABA. Figure 18 shows the responses recorded from an 
GABA
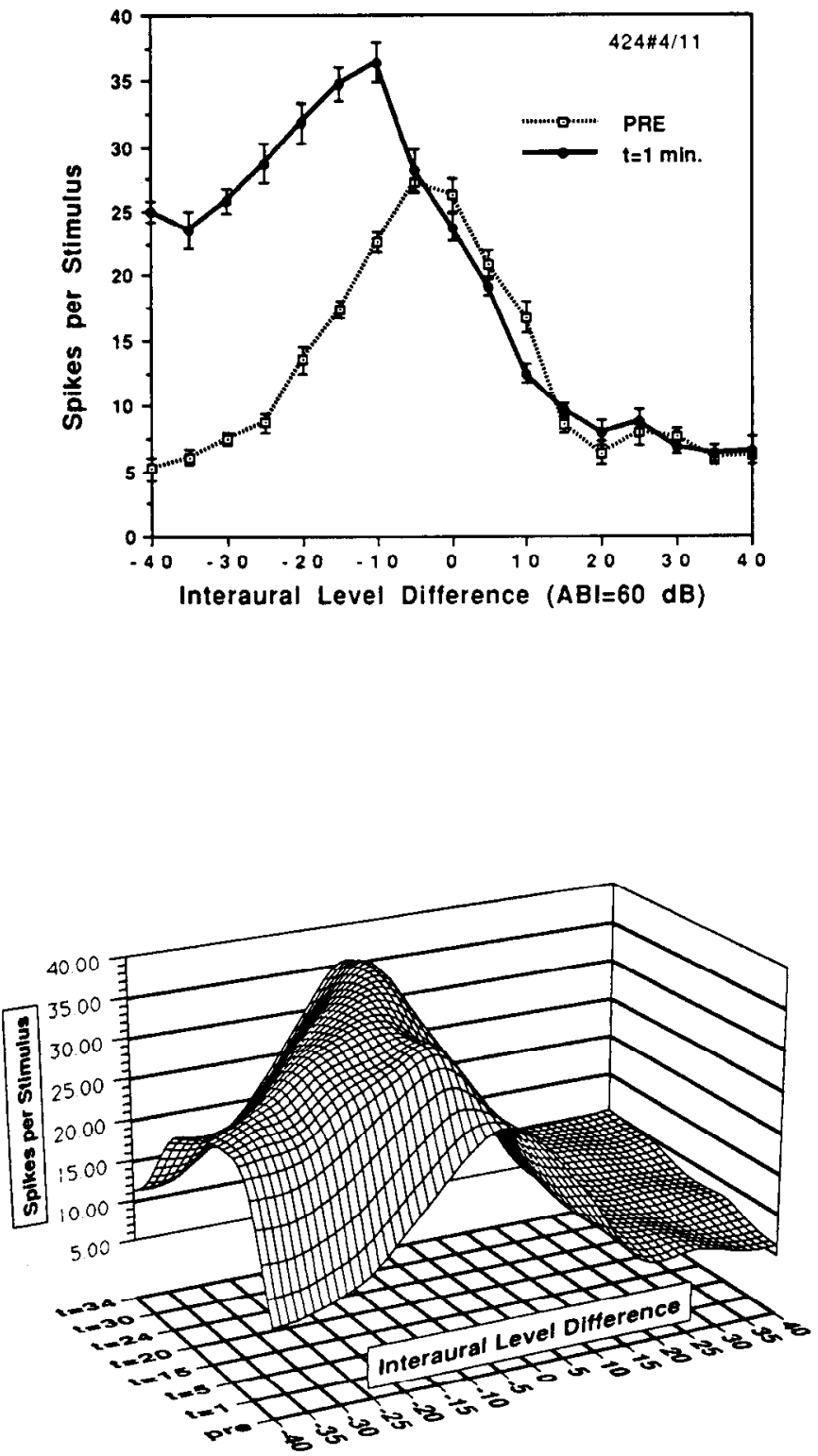
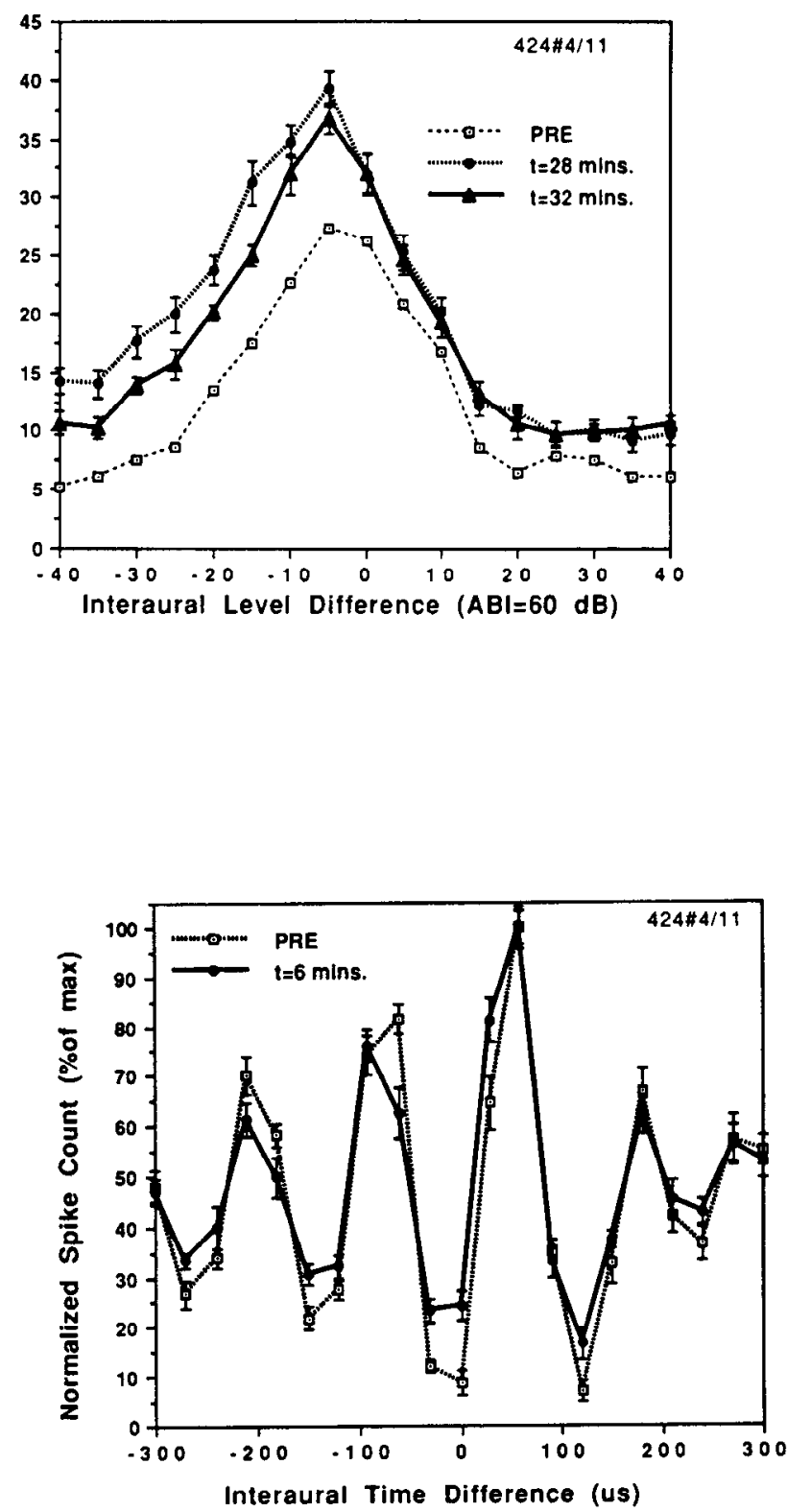

Figure 13. Injecting GABA into the contralateral VLVp affects responses in the ICx. GABA was injected into VLVp and the response in the contralateral ICx was recorded. Upper left, Response of the ICx neuron before, and 1 min after, the GABA injection: there is again an increase in the response at large ipsilateral ILD. Upper right, The effect slowly recovers after $32 \mathrm{~min}$. Lower left, A surface plot for the same experiment, showing the detailed temporal evolution of the effect with GABA. The surface was smoothed with a fourth-order spline. Lower right, Response to ITD at the neuron's optimal preinjection ILD was invariant. Stimulus was $4 \mathrm{kHz}$ tone in all cases. Spontaneous rate throughout, 0.0 spikes per stimulus.

ICx neuron before, after injecting one, and after injecting both VLVp. This experiment was also done by first injecting one VLVp several times until that nucleus was lesioned, and then injecting the other VLVp with GABA; the results from these experiments were the same. The previous experiments showed that inhibiting activity in the contralateral VLVp decreases the inhibition in ICx neurons by sounds loud at the ipsilateral ear. Inhibiting the ipsilateral VLVp decreases the inhibition by sounds loud at the contralateral ear. Bilateral inhibition of VLVp leads to decreased inhibition at either extreme ipsilateral or contralateral ILD (Fig. 18). Of 11 experiments in three owls in which VLVp was injected bilaterally, clear decreases in inhibition at both extremes of the ILD scale were seen in six cases.

\section{Discussion}

\section{Connectivity and physiology of $V L V p$}

The strategy of the present study was to select a level of processing in the owl's intensity pathway at the top of the hierarchy and ask how lower levels contribute to response tuning. Given neurons tuned to ILD in the owl's auditory space map in ICx, how can lower levels of processing generate such response properties? Hodological investigations were the first step in answering this question: what is the circuitry?

Previous studies showed that VLVp projected contralaterally to the medial shell of ICc (Adolphs, 1988) and suggested that VLVp might also project to the contralateral lateral shell of ICc 
BMI
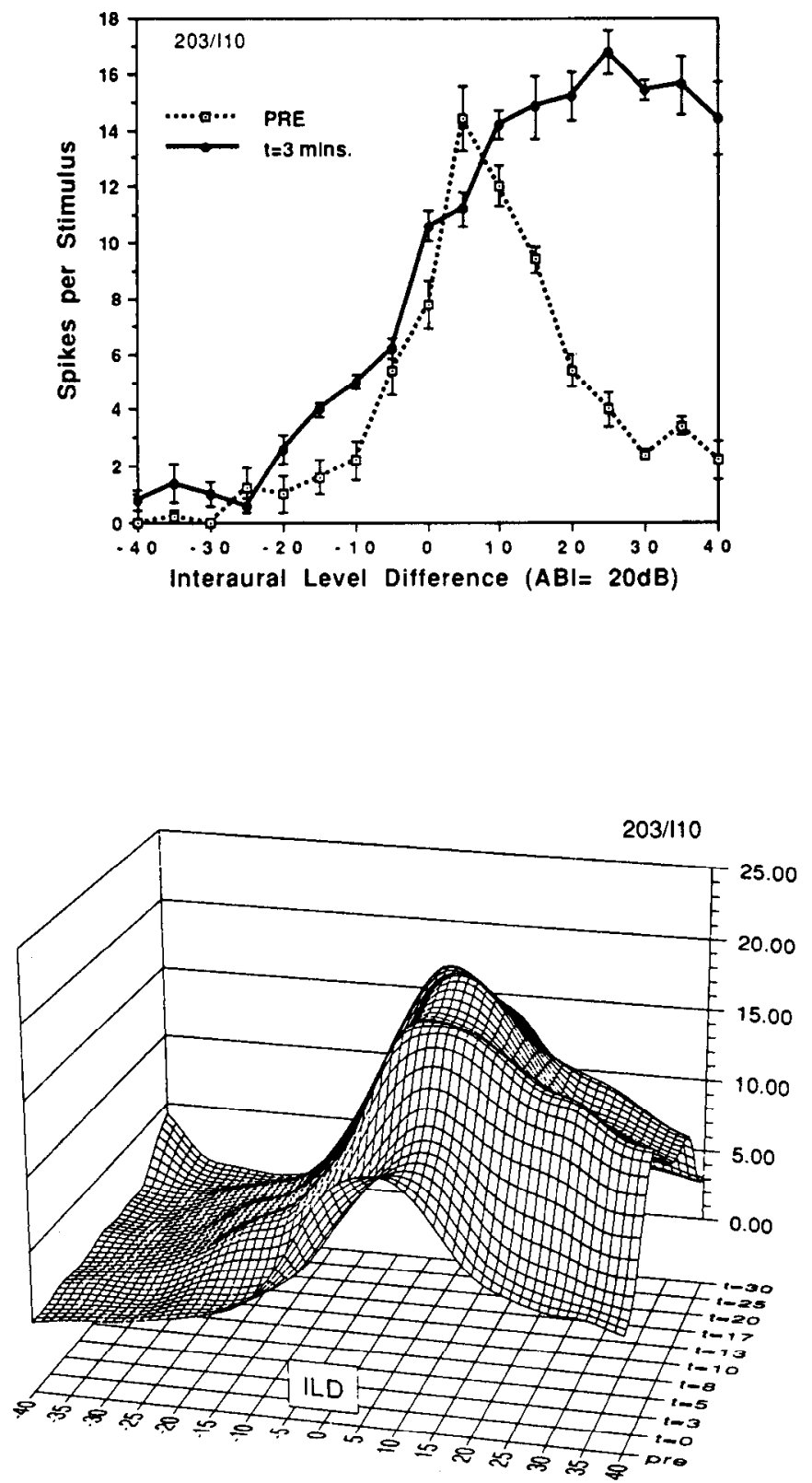
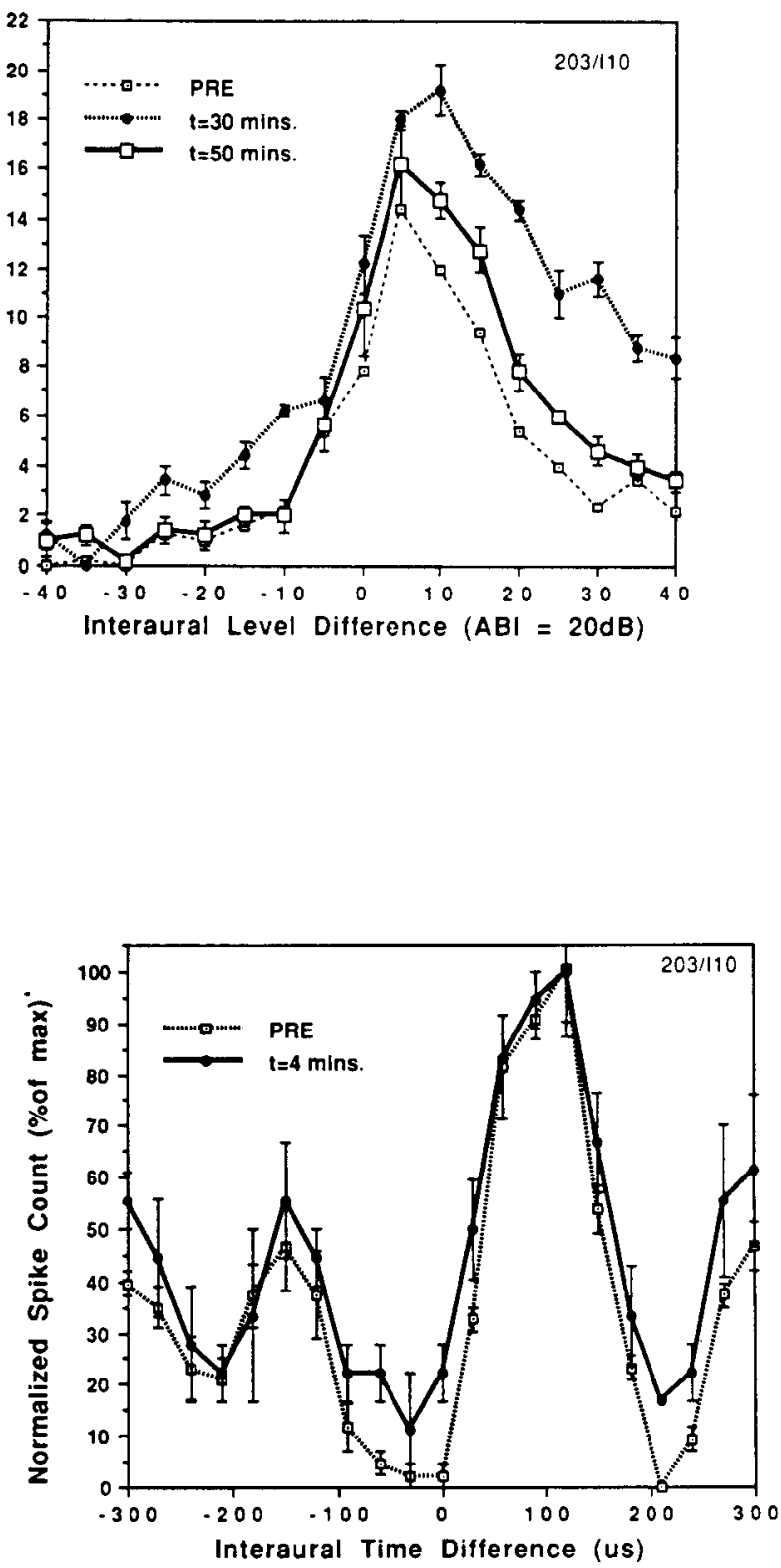

Figure 14. Injecting BMI into the contralateral VLVp affects responses in the ICx. BMI was injected into the contralateral VLVp while recording in the ICx. Upper left, Response of a single neuron in ICx before and $3 \mathrm{~min}$ after injecting BMI. There is an increase in the response to contralaterally loud ILD, the reverse of the effects seen with lidocaine and GABA. Upper right, The effect recovers after 50 min. Lower left, Surface plot of the same experiment showing temporal evolution; the surface was smoothed with a fourth-order spline. Lower right, Response to ITD at the neuron's optimal preinjection ILD was invariant. The stimulus was pseudorandom white noise in all cases. Spontaneous rate throughout, 1.0 spike per stimulus.

(R. Adolphs, unpublished observations; Takahashi and Keller, 1992). I found that VLVp projects bilaterally, and probably in a topography that preserves the mapping of frequency, onto the lateral shell of ICc. The lateral shell, in turn, is known to project to ICx. Neither the anterograde projections nor the functions of the medial shell have been investigated in any detail; the present study and previous results (Adolphs, 1988) suggest that it projects neither to the lateral shell nor to ICx. Figure 8 confirms Takahashi and Keller's (1992) finding that the VLVp are reciprocally connected. These circuits support a physiological model that I present below.
The generation of responses to binaural stimuli has recently been explored in VLVp, which is the first binaural site in the ascending intensity pathway. Manley et al. (1988) found that neurons in VLVp were inhibited by stimuli loud at the ipsilateral ear. Moreover, the strength of this inhibition changed in an orderly way across the nucleus: neurons in the top of (dorsal) VLVp are very strongly inhibited, while neurons near the ventral pole of the nucleus are nearly insensitive to, or only very weakly inhibited by, ipsilateral stimuli. All neurons in VLVp are excited by sounds at the contralateral car. The functional circuitry that leads to these response properties has been elucidated by Taka- 
A

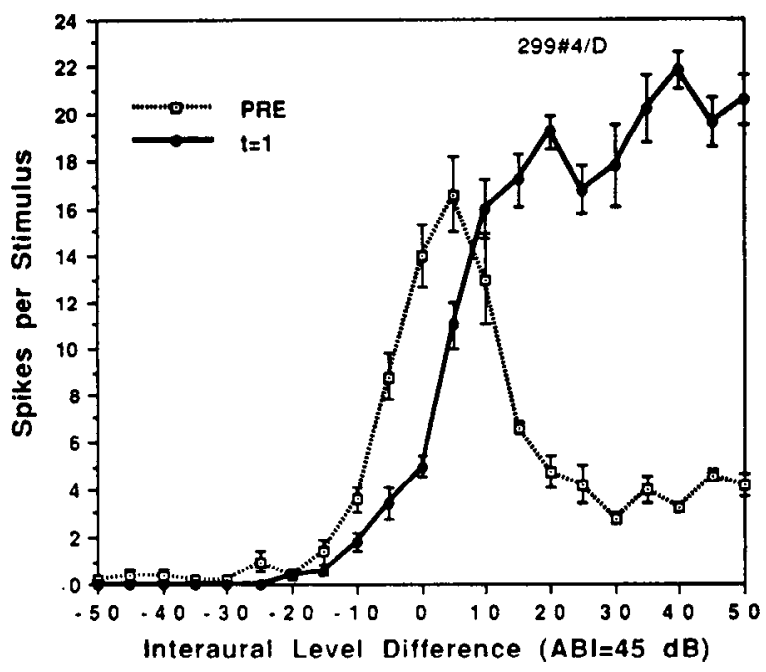

C

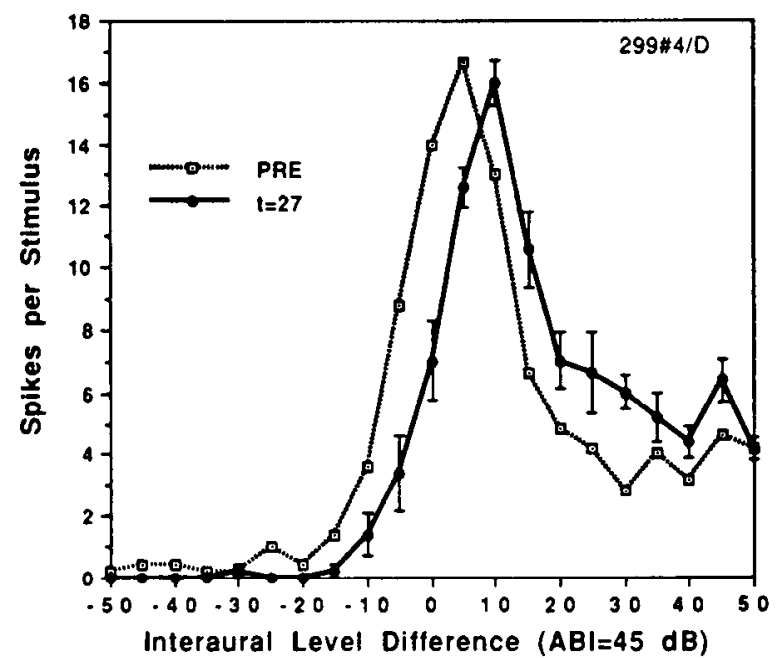

B
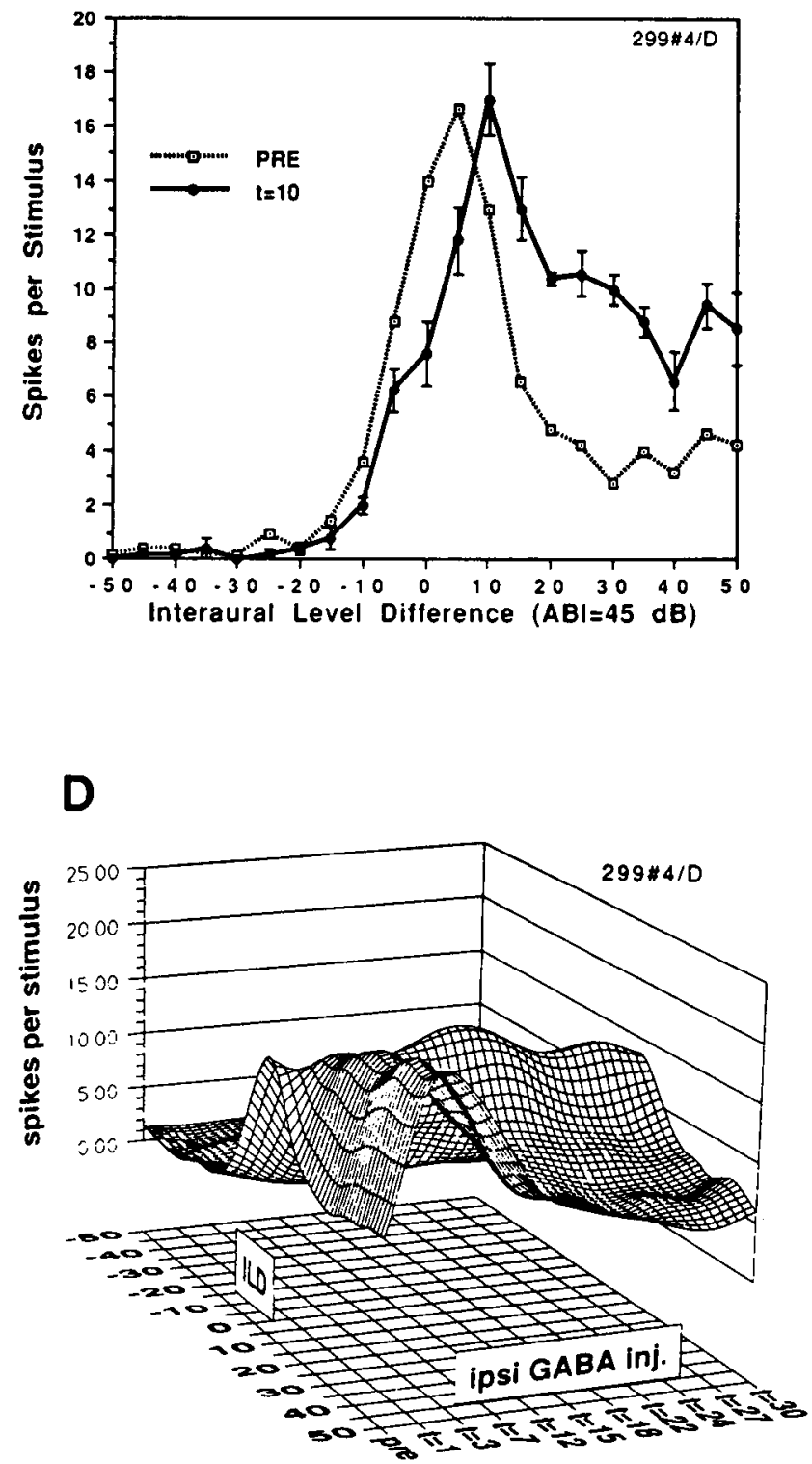

Figure 15. The ipsilateral VLVp provides inhibition to ICx: a single neuron in ICx before (PRE) and at various times after injecting GABA into the ipsilateral VLVp. $A$, There is an immediate block of the inhibition by sounds at large contralateral ILD. $B$ and $C$, This effect recovers over 27 min. $D$, Surface plot of the same experiment showing the temporal evolution of the effect; the surface was smoothed with a fourth-order spline. There was no change in the ITD tuning of the neuron after the injection (not shown). Stimulus was pseudorandom white noise. Spontaneous rate throughout, 0.0 spikes per stimulus.

hashi and Konishi (1988b), who showed that VLVp receives probably excitatory input from the contralateral nucleus angularis. The inhibitory input comes from the contralateral VLVp (Fig. 8), a result that has recently also been reported by Takahashi and Keller (1992), who used lidocaine instead of muscimol. The muscimol used in my experiments has the advantage over lidocaine that it affects only cell bodies proximal to the injection site, and not possible fibers of passage that could have been affected also with lidocaine. Because this polysynaptic inhibitory pathway from angularis to VLVp on the same side crosses the brain twice, it accounts for the inhibitory responses to ipsilateral sounds.

Figure 4 suggests that the two VLVps are connected in a crisscross fashion, with the ventral region of one VLVp pro- jecting to the dorsal region of the opposite VLVp. These results with the tracer PHA-L provide additional resolution to the recent anatomical studies of Takahashi and Keller (1992) and lend support to a theoretical model of how binaural responses are generated in VLVp (Spence and Pearson, 1989). The stronger dorsal inhibition seen in VLVp may have as its anatomical substrate the circuitry that Figure 4 suggests: dorsal cells are more inhibited than ventral cells because they receive more afferents from the opposite VLVp.

It is unlikely that interneurons serve to provide inhibition in VLVp, since neurons with the necessary response properties have not been found in any study (Moiseff and Konishi, 1983; Manley et al., 1988; Takahashi and Keller, 1992; Adolphs, unpublished observation). This raises the possibility that neurons 


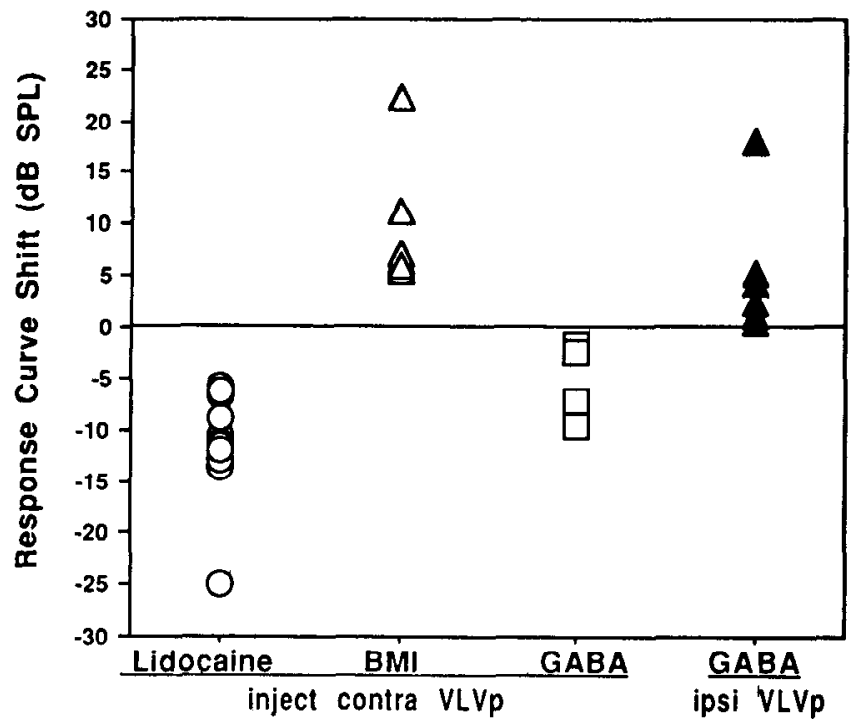

Figure 16. Shift of the response curve in the ICx with drug injections into VLVp. The maximal shift of the center-of-mass of the ILD-response function is plotted for all repeated experiments in which drugs were injected into VLVp and responses recorded in the ICX. The ordinate plots the maximal response curve shift, computed for each experiment as the maximal difference between the first moment of the preresponse curve and response curves after injecting drugs into VLVp. The first moment of the response curve is calculated as $\Sigma\left(x_{i} y_{i}\right) / \Sigma\left(y_{i}\right)$, where $x$ is the value of the ILD of the stimulus presented, and $y$ is the response (mean spikes per stimulus presentation). This gives the value of the ILD of the center-of-mass of the area under the curve. The ahscissa plots this response curve shift for experiments in which the contralateral VLVp was injected with lidocaine (circles; $n=11$; mean $=-11.3 ;$ SEM $=1.6$ ), BMI (open triangles; $n=7$; mean $=9.3$; SEM $=2.3$ ) or GABA (squares; $n=4$; mean $=-5.2 ; \mathrm{SEM}=1.9$ ), and in which the ipsilateral VLVp was injected with GABA (solid triangles; $n=7$; mean $=4.8$; $\mathrm{SEM}=2.3$ ). A positive response curve shift means the response to contralaterally loud stimuli was potentiated and/or the response to ipsilaterally loud stimuli was attenuated. A negative response curve shift means the response to ipsilaterally loud stimuli was potentiated and/or the response to contralaterally loud stimuli was attenuated. There was no change in spontaneous rate for any of these manipulations (data not shown).

in VLVp that are themselves inhibited may in turn project to the contralateral VLVp to inhibit cells there. This reciprocity, presumably most pronounced at the dorsoventral middle of VLVp, could result in responses with complex temporal structure (Takahashi and Keller, 1992).

Carr et al. (1989) reported that cells staining for glutamic acid decarboxylase (GAD) are more numerous in dorsal than in ventral VLVp. It is an intriguing possibility that this GAD-positive gradient relates to the physiological gradient of inhibition in VLVp. The involvement of GABA in VLVp neurotransmission, however, is unclear. The results of the present study show that VLVp cells can be inhibited by GABA and that there is GABAergic inhibition of VLVp cells that can be blocked by BMI (Fig. 7). However, this does not prove that the two VLVp inhibit each other via a GABAergic projection. The finding that BMI appears to disinhibit cells in VLVp uniformly at all ILD (Fig. $7 A$ ) rather suggests that there may be a tonic GABAergic inhibition that is independent of ILD. My results only show that $\mathrm{GABA}_{\mathrm{A}}$ receptor pharmacological agents can be used to alter the firing rate in VLVp; the physiological role of GABA neurotransmission in VLVp remains unknown.

There are confounding issues concerning the effects of BMI

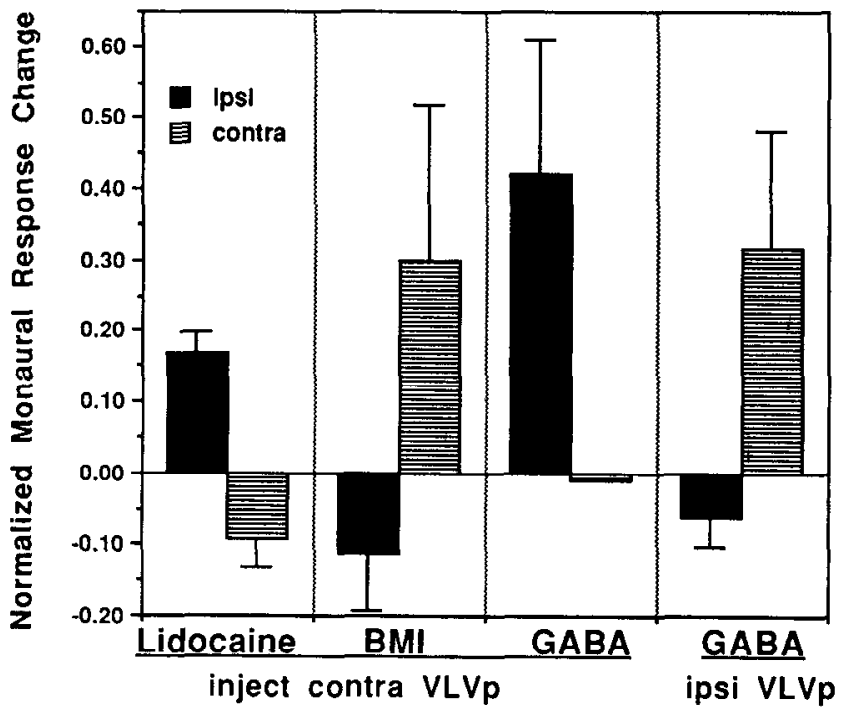

Figure 17. Injections of drugs into VLVp alter responses to monaural stimuli in the ICx. The mean changes in responses of ICx neurons to monaural ipsilateral (solid bars) or contralateral (hatched bars) stimuli and SEM are plotted. This is a summary of experiments in which the contralateral VLVp was injected with lidocaine $(n=11)$, BMI $(n=6)$, or GABA $(n=3)$, or in which the ipsilateral VLVp was injected with GABA $(n=7)$. The difference in the monaural response of an ICx cell before and after these injections of VLVp was calculated, and then normalized to the response of the ICx cell at optimal ILD (at an ABI equal to that of the monaural stimulation). Negative changes denote decreases in the monaural firing rate and generally underestimate the effect of induced inhibition since monaural firing rates of the ICx cells were near zero in most cases.

in VLVp (Fig. $7 A$ and later injection experiments). One possibility is that the cells within VLVp I found to respond to BMI were a different population from those cells that project to the lateral shell. In this case, the iontophoretic results would not allow an interpretation of the results of global injection of BMI in subsequent experiments. However, several points argue against such a complication. No heterogeneity in response properties in VLVp has been found (aside from the gradient of inhibition and the mapping of frequency). There is no evidence for functionally different subsets of neurons, with the exception of the gradient of inhibition. In particular, there are no neurons that are inhibited by contralateral sounds (as might be expected from a population of inhibitory interneurons). I also recorded the multiunit evoked response in VLVp through the syringe with which drugs were injected. BMI injection increased the global firing rate in VLVp as recorded through the syringe, also making it unlikely that BMI had effects only on a small set of neurons.

\section{Synthesis of responses in the inferior colliculus: the lateral shell}

Inhibitory mechanisms that contribute to restricting auditory receptive fields in space have been suggested by previous findings. Knudsen and Konishi (1978) found evidence of an inhibitory surround to the receptive fields of neurons in $\mathrm{ICx}$, as has also been found in the owl's optic tectum (Brainard et al., 1992). None of these studies address the locations of the neural sites where such inhibition might be implemented.

I used pharmacological methods to dissect functionally the processing of ILD. The results show that VLVp provides functional inhibition to the inferior colliculus such that peaked re- 
sponses to ILD are generated, but there are several different arrangements of neural circuits that could implement such functions.

I provide evidence that VLVp inhibits neurons in the lateral shell via a GABAergic projection (Figs. 9-11). In view of the response properties of the lateral shell, and of their alterations when activity in VLVp is manipulated, it appears that at least some lateral shell cells receive direct GABAergic inhibition. The inhibitory processes that sculpt sharply peaked responses to ILD appear to involve GABA, since blocking $\mathrm{GABA}_{\mathrm{A}}$ receptors locally results in large responses at extremes of ILD and a change in the shape of the binaural response curve (Fig. 9). Although inhibition at either ear can be blocked by BMI in most cells (Fig. 9C,D), there were several examples where inhibition by sounds loud at the ipsilateral ear could not be blocked (Figs. $9 B, 11)$. There are several possible explanations for this. The sites of inhibitory inputs on the lateral shell cell may be different for the two VLVp, such that inhibition by ipsilateral stimuli results from synapses that are relatively more distal to the recording site. The diffusion of BMI from the recording site to synaptic sites would then be different for spatially segregated inputs. Such a segregation of inputs could have interesting functional consequences. Another possible explanation for the results shown in Figures $9 B$ and 11 might be that the inhibition due to ipsilateral sounds is polysynaptic in the lateral shell. Perhaps only a subset of lateral shell neurons receive direct inhibition from the contralateral VLVp; this subset of cells in turn could provide all the excitatory input to a second set of cells in the lateral shell that then project to ICx. Cells in this second class of lateral shell cells receive excitatory input that simply copies the response function of the first set of lateral shell cells: there is only strong inhibition by ipsilateral sounds. The second set of lateral shell cells can then additionally receive direct inhibition from the ipsilateral VLVp (providing inhibition by sounds loud at the contralateral ear) to yield a response that is inhibited at either extreme of ILD: indirectly at large ipsilateral ILD, and directly at large contralateral ILD. Such a scheme, involving morc than one layer of processing in the lateral shell, would be entirely consistent with the heterogeneity of responses to ILD seen in that structure (Fujita and Konishi, 1989). Preliminary observations (Adolphs, unpublished observations; J. Mazer, personal communication) suggest that the responses of lateral shell cells to ILD resemble those of VLVp (ipsilateral inhibition) medially and progressively resemble those of ICX (bilateral inhibition) at more lateral positions in the nucleus. However, to distinguish between the above possibilities, it will be necessary to examine the inputs to single cells in the lateral shell systematically. Neither the gross anatomical tracing studies nor the extracellular physiology of the present study can address these issues.

Similar considerations can explain why only inhibition at

Figure 18. Bilateral injections of VLVp affect the ICx. $A$, Response of ICX neuron before (PRE) and $3 \mathrm{~min}$ after injecting GABA into the ipsilateral VLVp. There is a slight attenuation of the inhibition at large contralateral ILD. $B$, Response 9 min after the ipsilateral VLVp injection, and 2 min after an additional injection of GABA into the contralateral VLVp. There is attenuation of inhibition at large contralateral and ipsilateral ILD. $C$, The effect shows partial recovery $30 \mathrm{~min}$ after the first injection. The response to ITD at the neuron's optimal preinjection ILD was invariant (not shown). Stimulus was pseudorandom white noise. Spontaneous rate throughout, 0.0 spikes per stimulus.

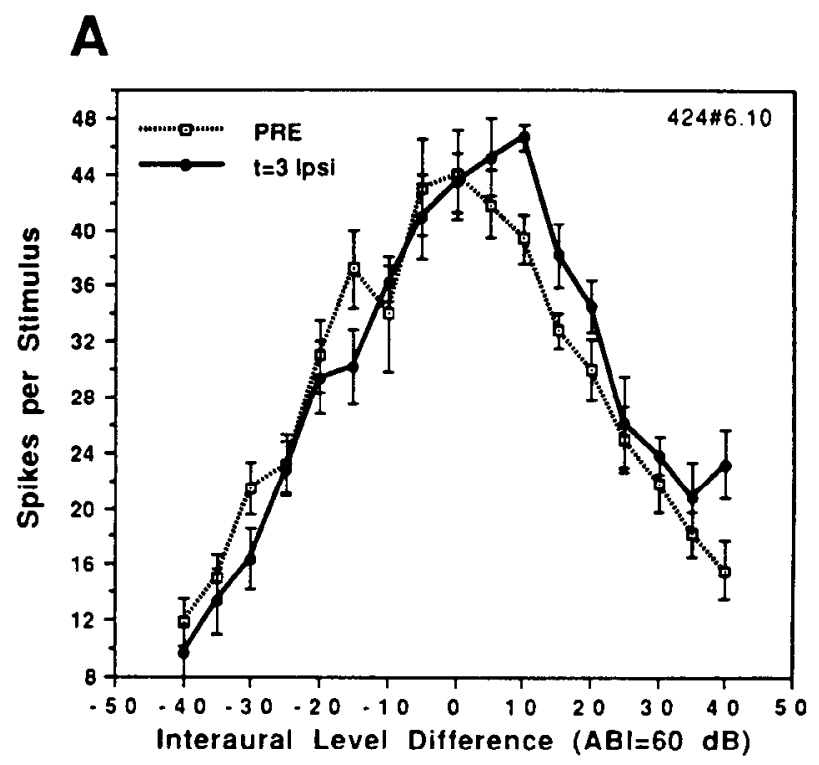

\section{B}
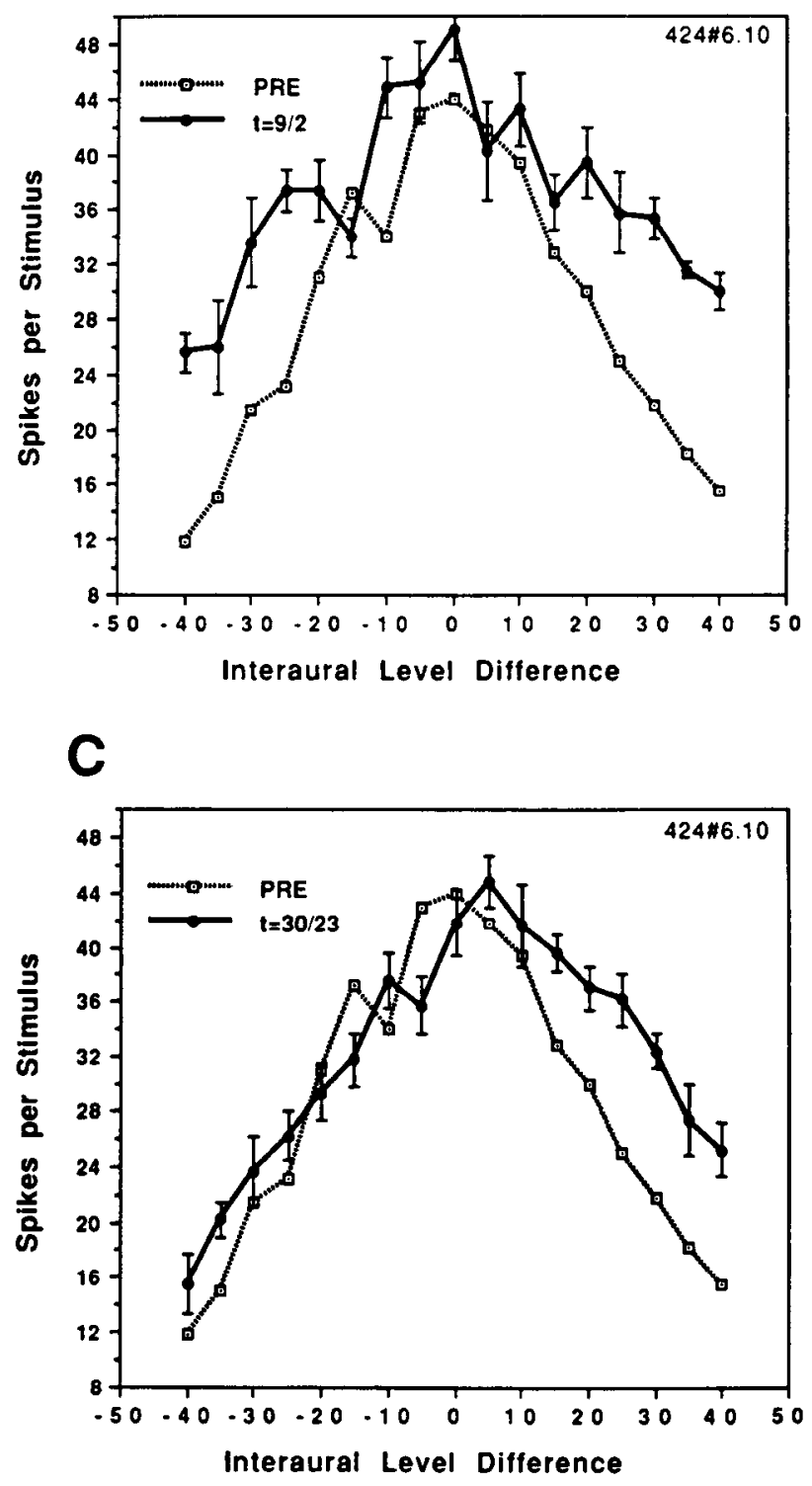

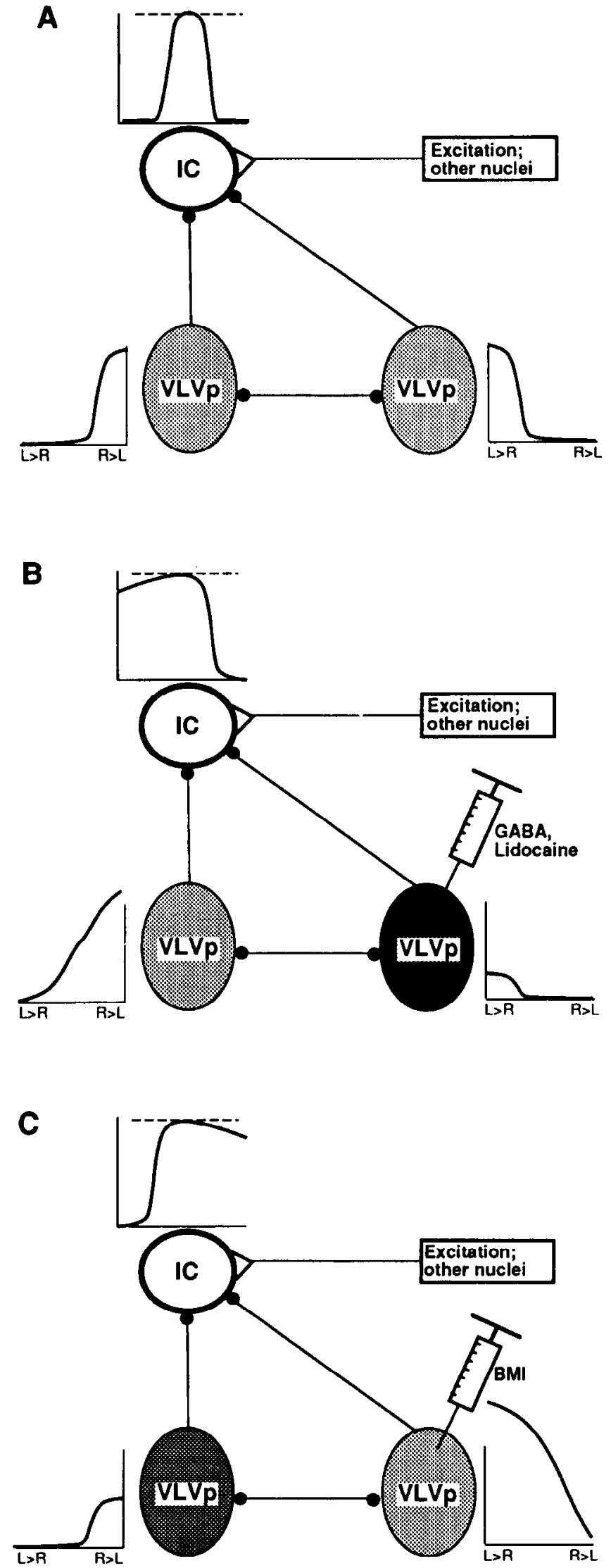

Figure 19. Model of the contribution of VLVp to selectivity for ILD in the inferior colliculus. $A$, Schematic of the bilateral projections from VLVp to the inferior colliculus (IC). It is proposed that the IC obtains contralateral ILD can be manipulated in the experiment shown in Figure 11. In this case, the lateral shell cell would have to receive either anatomically segregated input, or both poly- and monosynaptic input, from one VLVp. Given that cells in VLVp are of different response types in dorsal and in ventral portions of the nucleus, such differential projections by cells in the same VLVp could again result in architectures with important functional consequences. Experiments in which lateral shell cells are recorded intracellularly could shed more light on the cellular computations in the lateral shell.

GABAergic inhibition has also been reported at many levels of the pathway that processes ITD in the owl (Mori et al., 1990; Fujita and Konishi, 1991). It is not known if inhibitory transmitters other than GABA are additionally involved, or the nature of the excitatory transmitters in any of the owl's auditory pathways.

\section{Synthesis of responses in the inferior colliculus: the ICX}

The heterogeneity of responses to ILD, and the lack of any clear map of ILD or of sound source elevation make the response properties of neurons in the lateral shell difficult to interpret at the global level of the experiments of this study. The only conclusions that can be drawn are that (1) VLVp bilaterally projects directly to at least some neurons in the lateral shell, (2) lateral shell cells can be inhibited by VLVp, and (3) at least some of this inhibition is direct and GABAergic. The previous considerations suggest the possibility that some of the circuitry that shapes responses to ILD is intrinsic to the lateral shell, and that the projection from VLVp to the ICx may be more than disynaptic. A clearer functional view of how inputs from VLVp (polysynaptically) sculpt tuned responses to ILD is obtained by examining cells in $\mathrm{ICx}$.

Figures 12-18 present experiments that show that the VLVp on either side functions to inhibit responses at either extreme of ILD. For small ILD, neither VLVp provides strong inhibition, and the peaked response that encodes sound source elevation is seen in the ICx. The reciprocal connection between the two VLVps has the consequence that the relative levels of activity between the VLVps will influence the position of the peak of the response in the ICx. This is seen in Figure 12: injecting

inhibitory input (dots) from VLVp, and excitatory input (open triangle) from unknown sources. The excitation need not be selective for ILD (broken line on response-ILD graph for IC). Rather, selectivity for ILD is shaped by inputs from the VLVp to generate the bell-shaped curve (response vs. ILD, top graph). It is also known that the VLVp on each side are connected reciprocally and inhibit each other, resulting in sigmoid response curves to ILD in VLVp. This functional model oversimplifies the actual circuitry, which involves at least an additional synapse in the lateral shell before tuned responses are generated. The abscissa on all graphs represents stimuli loud at the left ear on the left side, and stimuli loud at the right ear on the right. The results from injecting the VLVp with lidocaine, GABA, or BMI can be explained with this scheme. $B$, Injecting the contralateral VLVp with GABA or lidocaine attenuates the response within the nucleus (dark shading), and may variably increase the response in the other VLVp. Since the inhibition that the injected VLVp normally provides is now less, the ILD-selective neuron in the colliculus will respond at ipsilaterally loud ILD that previously inhibited it. $C$, Similarly, injecting BMI into the VLVp increases the response within that nucleus, and may decrease the response in the other VLVp. The neurons in the colliculus show a change in response that is qualitatively the converse of that seen in $A$. A similar effect is seen when the ipsilateral VLVp is injected with GABA, since the activity patterns in the two VLVp will be similar. 
lidocaine not only decreases inhibition at large ipsilateral ILD, but also increases inhibition at large contralateral ILD; together these effects actually shift the peak to the left (Fig. 12, left top and left bottom). These results are what one would predict given the commissural inhibitory connection between the two VLVps. Anesthetization of one VLVp results in decreased inhibition both in the contralateral IC and in the contralateral VLVp; the increased activity in the contralateral VLVp can then in turn account for the increased inhibition seen on the right side of the curve in the ICx.

The shift of the peak of the curve in the ICx was most pronounced with injections of lidocaine, and either absent (Figs. 13,14 ) or only very weak (Fig. 15) with BMI or GABA. Several factors could account for these differences in detail between the effects seen with lidocaine on the one hand, and with GABAreceptor drugs on the other. One important difference is that lidocaine blocks fibers of passage as well as activity in all cell bodies; this would necessarily result in a functional disconnection of the two VLVps since they are connected by a bundle of fibers. On the other hand, GABA or BMI may have larger influences on cells that project to the IC directly than on the indirect projection via the opposite VLVp, and these drugs will not necessarily disconnect the two VLVps since they do not affect fibers.

Figure 19 presents a schematic functional model that summarizes the results observed in the ICx. Cells in the lateral shell of the inferior colliculus receive excitatory input from unknown and probably diverse sources. This excitation need not be tuned to ILD, but rather results in a significant response at all ILDs. The role of VLVp is to provide inhibition, such that cells postsynaptic to the lateral shell in ICx become binaurally exclusive and have sharply peaked response curves to ILD. Much of the circuitry that implements the bilateral inhibition is likely to involve several steps intrinsic to the lateral shell; this article does not address these steps and they are not indicated in the model. The results of all experiments in which the activity within VLVp was manipulated can be interpreted within this scheme (Fig. 19B,C). The results of this study suggest that a large part of the phenomenological facilitation seen in the responses of ICx cells may simply be an unmasking of excitation. It is possible that inhibitory mechanisms alone can account for the sharp tuning that ICx cells show and that excitatory input shows no nonlinearities as a function of ILD. Again, more rigorous investigations that employ intracellular recordings will be needed to establish these proposals.

The source of excitatory input to the lateral shell that is schematically indicated in Figure 19 has several preliminary candidates. Takahashi et al. (1989) demonstrated an input to the lateral shell from the contralateral core of ICc. This projection is likely to be excitatory and also shows no tuning to ILD (but only to ITD). My preliminary studies suggest that inputs from the lateral lemniscus excite lateral shell cells; nucleus angularis could be one source of such inputs that would provide excitation that is not tuned to ILD. Further experiments of a design similar to the ones reported here could elucidate the nuclei that provide excitatory input to the lateral shell.

There are other models that have attempted to explain the synthesis of ILD tuning in the ICX. One of the most detailed is the model of Pearson et al. (1990). This model assumes a nonlinear gradient of inhibition in VLVp and then takes the derivative of the response across the dorsoventral axis of the nucleus' tissue to generate a peak of activity in ICx. The gradient of inhibition in VLVp, according to this model, can be visualized as a sigmoid function: cells dorsally in VLVp are very strongly inhibited, cells ventrally are not inhibited, and near the middle of VLVp there is a sharp change in the strength of inhibition. Taking the derivative of a sigmoid function will yield a peaked function, with the peak located at the value of ILD at which the strength of inhibition in VLVp was changing most rapidly. Detailed simulations of this model, which have been presented elsewhere (Pearson et al., 1990), give results in close agreement with some of the data.

A simpler model, which does not make any requirements on the precise shape of the gradient of inhibition in VLVp (it could be linear), could also qualitatively account for the results ( $S$. Volman, personal communication). This model simply takes the difference between the responses in the dorsal and ventral VLVp. Since cells in the dorsal VLVp are inhibited more strongly than cells in the ventral VLVp (Manley et al., 1988), such an algebraic subtraction will yield a nonzero difference (a peak) at those ILDs at which the curves differ most. This difference dictates the position of the peak in the ICx. Both this model and the one by Pearson et al., have the virtue of providing a role for the gradient of inhibition found in VLVp. However, they do not explain the results I report here that ipsilateral and bilateral injections of VLVp affect responses in ICx: the activity in the contralateral VLVp should be sufficient to account for the tuned response in ICX if the gradient of inhibition is utilized according to the above models. They would also predict that injecting dorsal or ventral regions of VLVp should have different effects, which is not borne out by experiments so far.

A different model that attempts to explain synthesis of a peak in the ICx convolves the response of one VLVp with that of the VLVp on the opposite side (T. Takahashi originated the idea, personal communication). Though multiplying the response functions of the two VLVps in this manner does generate a peaked function, this model runs counter to the results reported in the present study that VLVp provides inhibition to the colliculus.

The tuning of ICx neurons to ILD does not shift with average binaural intensity, or with ITD. The latter invariance can be explained by the independence of the time and intensity pathways, a processing architecture that receives further support from the finding of this study that $V L V p$ affects responses to ILD, but not to ITD. The invariance of ILD tuning with ABI would appear to be a good design strategy, since the system should encode where a sound is coming from independent of how loud the sound is. Neurons in VLVp, however, are sensitive to both ILD and ABI (Manlcy ct al., 1988), suggesting that this invariance emerges only at the level of the inferior colliculus. The model I present here could qualitatively account for this observation. The response to ILD in one VLVp will shift with ABI symmetrically to the way the response shifts in the VLVp on the opposite side of the brain. Bilateral inhibition of collicular cells by VLVp could thus cancel any shift of ILD with ABI by symmetry.

The model that I present in Figure 19 is the only model that accounts for the hodological and physiological results reported. However, none of the other models are conclusively ruled out. It is possible that several, different models in combination may be a correct description of the mechanisms that underlie peaked ILD-response functions. Further experiments on the microcircuitry of connections to and within the lateral shell, and of the transmitters used, in conjunction with computer simulations 
once such data are available, all are necessary to decide the status of these models.

\section{Comparison with mammals and with other owl species}

The auditory brainstem of the barn owl shares several features in common with mammalian sensory systems. Neural maps of sensory space, parallel processing streams, and hierarchical architectures are found both in the owl (Konishi, 1986; Konishi et al., 1988) and in such well-studied mammalian sensory systems as the primate visual system (DeYoe and Van Essen, 1988; Van Essen et al., 1990) and the biosonar system of the bat (Suga, 1988, 1989). Aside from these gross processing similarities, however, it is difficult to find counterparts to the owl's auditory brainstem circuitry. The auditory brainstem of mammals is both anatomically and physiologically more complex.

Psychophysical and acoustic studies suggest that mammals use ILD to localize high-frequency sources in azimuth (Stevens and Newman, 1936; Caseday and Neff, 1973; Martin and Webster, 1987) and possibly also to localize spectrally complex sounds in two dimensions (Martin and Webster, 1989). In mammals, it appears that the ILD tuning of cells can also be a function of average binaural intensity (Semple and Kitzes, 1987; Irvine and Gago, 1990) and of ITD (Yin et al., 1985; Caird and Klinke, 1987; Pollak, 1988). The barn owl has the advantage that the cue of ILD has a particularly clear neuroethological relevance in the localization of sound sources along one coordinate of auditory space (Moiseff, 1989a,b). Unlike in mammals, ILD in the owl is processed in a pathway completely separate from processing of ITD.

It has been suggested that some of the auditory nuclei in the owl are andogous to nuclei found in mammals; in particular, it has been suggested that VLVp might be analogous to the dorsal nucleus of the lateral lemniscus (DNLL) in mammals, on the basis of response properties and hodology (Takahashi and Konishi, 1988b; Takahashi and Keller, 1992). Most neurons in DNLL respond to binaural stimuli (Aitkin et al., 1970); nearly all are excited by sounds loud at the contralateral ear. Some low-frequency neurons in the nucleus are sensitive to phase disparities, but nearly all neurons tuned to higher frequencies are excited by the contralateral car and either unresponsive to or inhibited by the ipsilateral ear (Brugge et al., 1970). These binaural response classes are also common in the inferior colliculus in mammals, and one proposal is that the DNLL provides inhibitory input both to the colliculus and to the opposite DNLL (Shneiderman et al., 1988). There is support for the inhibitory role of DNLL from findings that many of its projection neurons appear to be GABAergic (Adams and Mugnaini, 1984; Moore and Moore, 1987).

Another mammalian nucleus with binaural responses sensitive to ILD is the lateral nucleus of the superior olive (LSO), which is excited by sounds loud at the ipsilateral ear and inhibited by sounds loud at the contralateral ear (Boudreau and Tsuchitani, 1968), just the opposite of VLVp. Like VLVp, the $\mathrm{LSO}$ receives a direct excitatory projection and an indirect inhibitory projection from cochlear nuclei (Glendenning et al., 1985; Finlayson and Caspary, 1989). This hodology supports models in which ILD coding is derived by a comparison between the firing rates of neurons in cochlear nuclei on each side (Colburn and Moss, 1981). The inhibition appears to be glycinergic (Caspary, 1990), although both GABA and glycine are found in the LSO (Helfert et al., 1989). Recent studies of the LSO in brain slice preparations have confirmed that inhibition of LSO cells is glycinergic, and that excitation appears to be mediated by non-NMDA glutamate receptors (Wu and Kelly, 1992). Some studies have suggested a gradient of inhibitory input in the LSO across the mediolateral dimension, such that medial (high-frequency) LSO neurons receive denser glycinergic inputs than do more lateral (lower-frequency) regions (Glendenning et al., 1985; Sanes et al., 1987). A recent report suggests, however, that the physiology may not exhibit any inhibitory gradient; low-frequency neurons in the LSO appear to exhibit binaural inhibition, although this is also sensitive to phase (Finlayson and Caspary, 1991).

Both the DNLL and the LSO project to the ICc in mammals. The LSO projects bilaterally to the inferior colliculus (BrunsoBechtold et al., 1981; Glendenning and Masterton, 1983; Moore, 1988) and appears to provide both glycinergic inhibition and non-NMDA receptor-mediated excitation (Saint Marie et al., 1989). The DNLL also projects bilaterally to the ICc (Roth et al., 1978; Shneiderman et al., 1988), and may use GABA as an inhibitory transmitter (Adams and Mugnaini, 1984).

It is interesting to compare the barn owl to other owl species. Though no other owl has been studied as intensively as the barn owl, there are physiological data on the great horned (Volman and Konishi, 1989), long-eared (Volman and Konishi, 1990), and saw-whet owl (Wise et al., 1988). The usc of ILD as a cue for elevation relies on a vertical asymmetry in the directional sensitivities of the ears at high frequencies (Payne, 1971; Coles and Guppy, 1988; Moiseff, 1989a). Ear asymmetry appears to have arisen independently in the evolution of several species of owl (Norberg, 1977; Volman, 1990). Volman and Konishi (1989) examined the tuning properties of neurons in the inferior colliculus of the great horned owl, which has symmetrical ears, and found that in this owl auditory spatial receptive fields are not limited in elevation. In view of the utility of ears with vertical asymmetry, it is surprising that no animals other than some owls appear to have evolved this feature, suggesting that perhaps aspects of the owl's auditory system are preadapted to take advantage of the occurrence of peripheral asymmetries (Volman, 1990). Support for this hypothesis comes from the finding that cells in the great horned owl's ICx, while having auditory spatial receptive ficlds that arc unlimited in elevation, show tuning to ILD. Perhaps owls with symmetrical ears possess much of the same brainstem circuitry as the barn owl, but their peripheral specializations do not support the use of ILD as a cue for elevation.

What purpose might tuning for ILD serve in a species such as the great horned owl? Two possibilities that Volman and Konishi (1989) point out are that ILD serves as a cue for horizontal sound source position that is supplementary to ITD, or that the binaurally exclusive response properties seen in the ICx serve to provide a window within which other responses are permitted. For example, inhibition of monaural responses could serve to filter out spontaneous activity that is afferent from lower, monaurally responsive nuclei. Since the computation of ITD can only be made for binaural stimuli, such filtering could serve to increase the signal-to-noise ratio of coding for ITD in the ICx. Such a function is also not ruled out in the barn owl, although in this species it is clear that ILD codes for vertical source location as well. Future behavioral studies could address some of these issues. The results and models I have presented would predict that blocking activity in VLVp would lead to errors predominantly in localizing sounds in elevation, where tuning to ILD represents vertical source position. If binaural 
exclusiveness serves other purposes, such an experiment might reveal an impairment in localizing sounds anywhere in space.

\section{References}

Adams JC, Mugnaini E (1984) Dorsal nuclcus of the lateral lemniscus: a nucleus of GABAergic projection neurons. Brain Res Bull 13:585590.

Adolphs $\mathrm{R}$ (1988) Processing of interaural level differences in the inferior colliculus of the barn owl. Soc Neurosci Abstr 14:1097.

Adolphs R (1991) Acetylcholinesterase differentially stains parallel pathways in the barn owl's auditory brainstem. Soc Neurosci Abstr 17:300.

Adolphs R (1993) Acetylcholinesterase staining differentiates functionally distinct auditory pathways in the barn owl. J Comp Neurol 329:365-377.

Aitkin LM, Anderson DJ, Brugge JF (1970) Tonotopic organization and discharge characteristics of single neurons in nuclei of the lateral lemniscus of the cat. J Neurophysiol 33:421-440.

Boudreau JC. Tsuchitani C. (1968) Binaural interaction in the cat superior olive S segment. J Neurophysiol 31:442-454.

Brainard MS, Knudsen EI, Esterly SD (1992) Neural derivation of sound location: resolution of spatial ambiguities in binaural cues. $J$ Acoust Soc Am 91:1015-1027.

Brugge JF, Anderson DJ, Aitkin LM (1970) Responses of neurons in the dorsal nucleus of the lateral lemniscus of cat to binaural tonal stimulation. J Neurophysiol 33:441-458.

Brunso-Bechtold JK, Thompson JK, Masterton RB (1981) HRP study of the auditory afferents ascending to central nucleus of the inferior colliculus in cat. J Comp Neurol 197:705-722.

Caird D, Klinke R (1987) Processing of interaural time and intensity differences in the cat inferior colliculus. Exp Brain Res 68:379-392.

Carr CE, Fujita I, Konishi M (1989) Distribution of GABAergic neurons and terminals in the auditory system of the barn owl. J Comp Neurol 286:190-207.

Caspary DM (1990) Electrophysiological studies of glycinergic mechanisms in auditory brainstem structures. In: Glycine neurotransmission (Otterson OP, Storm-Mathisen J, eds), pp 453-483. New York: Wiley.

Caspary DM, Rybak LP, Faingold CI. (1985) The effects of inhibitory and excitatory amino-acid neurotransmitters on the response propertics of brainstem auditory neurons. In: Auditory biochemistry (Drescher DG, ed). Springfield, MA: Thomas.

Casseday JH, Neff WD (1973) Localization of pure tones. J Acoust Soc Am 54:365-372.

Colburn HS, Moss PJ (1981) Binaural interaction models and mechanisms. In: Neuronal mechanisms of hearing (Syka J, Aitkin L, eds), pp 283-288. New York: Plenum.

Coles RB, Guppy A (1988) Directional hearing in the barn owl (Tyto alba). J Comp Physiol [A] 163:117-133.

DeYoe EA, Van Essen DC (1988) Concurrent processing streams in monkey visual cortex. Trends Neurosci 11:219-226.

Ericson H, Blomqvist A (1988) Tracing of neuronal connections with cholera toxin subunit B: light and electron microscopic immunohistochemistry using monoclonal antibodies. J Neurosci Methods 24:225235.

Finlayson PG, Caspary DM (1989) Synaptic potentials of chinchilla lateral superior olivary neurons. Hearing Res 38:221-228.

Finlayson PG, Caspary DM (1991) Low-frequency, neurons in the lateral supcrior olive exhibit phase-sensitive binaural inhibition. $\mathbf{J}$ Neurophysiol 65:598-605.

Fujita I, Konishi M (1989) Transition from single to multiple frequency channels in the processing of binaural disparity cues in the owl's midbrain. Soc Neurosci Abstr 15:114.

Fujita I, Konishi M (1991) The role of GABAergic inhibition in processing of interaural time difference in the owl's auditory system. $J$ Neurosci 11:722-739.

Gerfen CR, Sawchenko PE (1983) An anterograde neuroanatomical tracing method that shows the detailed morphology of neurons, their axons, and terminals: immunohistochemical localization of an axonally transported plant lectin, Phaseolus vulgaris leucoagglutinin (PHA-L). Brain Res 209:219-238.

Glendenning KK, Masterton RB (1983) Acoustic chiasm; efferent projections of the lateral superior olive. J Neurosci 3:1521-1537.

Glendenning KK, Hutson KA, Nudo RJ, Masterton RB (1985) Acous- tic chiasm. II. Anatomical basis of binaurality in the lateral superior olive of the cat. J Comp Neurol 232:261-286.

Helfert RH, Bonneau JM, Wenthold RJ, Altschuler RA (1989) GABA and glycine immunoreactivity in the guinea pig superior olivary complex. Brain Res 501:269-286.

Irvine DRF (1987) A comparison of two methods for the measurement of neural sensitivity to interaural intensity differences. Hearing Res 30:169-180.

Irvine DRF, Gago G (1990) Binaural interaction in high-frequency neurons in inferior colliculus of the cat: effects of variations in sound pressure level on sensitivity to interaural intensity differences. Neuroscience 63:570-591.

Karnovsky MJ, Roots L (1964) A "direct-coloring" thiocholine method for cholinesterases. J Histochem Cytochem 12:219-221.

Kat7. LC, Burkhalter A, Dreyer WJ (1984) Fluorescent latex microspheres as a retrograde marker for in vivo and in vitro studies of visual cortex. Nature 310:498-500.

Knudsen EI (1983) Subdivisions of the inferior colliculus in the barn owl (Tyto alba). J Comp Neurol 218:174-186.

Knudsen EI, Konishi M (1978) A neural map of auditory space in the owl. Science 200:795-797.

Konishi M (1986) Centrally synthesized maps of sensory space. Trends Ncurosci 4:163-168.

Konishi M, Takahashi T, Wagner H. Sullivan WE, Carr CE (1988) Neurophysiological and anatomical substrates of sound localization in the owl. In: Auditory function (Edelman G, Gall W, Cowan W, eds), pp 721-746. New York: Wilcy:

Manley GA, Koppl C, Konishi M (1988) A neural map of interaural intensity differences in the brain stem of the barn owl. J Neurosci 8:2665-2676.

Martin RL, Webster WR (1987) The auditory spatial acuity of the domestic cat in the interaural horizontal and median vertical planes. Hearing Res 30:239-252.

Martin RL, Webster WR (1989) Interaural sound pressure level differences associated with sound-source locations in the frontal hemifield of the domestic cat. Hearing Res 38:289-302.

Moiseff A (1989a) Binaural disparity cues a vailable to the barn owl for sound localization. J Comp Physiol [A] 164:629-637.

Moiseff A (1989b) Bi-coordinate sound localization by the barn owl. J Comp Physiol [A] 163:639-644.

Moiseff A, Konishi M (1983) Binaural characteristics of units in the owl's brainstem auditory pathway: precursors of restricted spatial receptive fields. J Neurosci 3:2553-2562.

Moore DR (1988) Auditory brainstem of the ferret: sources of projections to the inferior colliculus. J Comp Neurol 269:342-354.

Moore JK, Moore RV (1987) Glutamic acid decarboxylasc-like immunoreactivity in brainstem auditory nuclei of the rat. J Comp Neurol 260:157-174.

Mori K, Fujita I, Konishi M (1990) GABAergic inhibition contributes to non-linear summation among multiple frequency channels in the barn owl's inferior colliculus. Soc Neurosci Abstr 512.7.

Mueller CM, Scheich H (1988) Contribution of GABAcrgic inhibition to the response characteristics of auditory units in the avian forebrain. J Neurophysiol 59:1673-1689.

Norberg RA (1977) Occurrence and independent evolution of bilateral ear asymmetry in owls and implications on owl taxonomy. Philos Trans R Soc Lond [Biol] 973:375-408.

Payne RS (1971) Acoustic location of prey by barn owls. J Exp Biol 54:535-573.

Pearson JC, Spence CD, Adulphs R (1990) The computation of sound elevation in the barn owl: model and physiology. Soc Neurosci Abstr 16:299.3.

Pollak G (1988) Time is traded for intensity in the bat's auditory system. Hearing Res 36:107-124.

Rath GL, Aitkin LM, Andersen RA, Merzenich MM (1978) Some features of the spatial organization of the central nucleus of the inferior colliculus of the cat. J Comp Neurol 182:661-680.

Saint Marie RL, Ostapoff EM, Morest DK, Wenthold RJ (1989) Glycine-immunoreactive projection of the cat lateral superior olive: possible role in midbrain ear dominance. J Comp Neurol 279:382-396.

Sanes DH, Geary WA, Wooten GF, Rubel EW (1987) Quantitative distribution of the glycine receptor in the auditory brain stem of the gerbil. J Neurosci 7:3793-3802.

Semple MN, Kitzes LM (1987) Binaural processing of sound pressure level in the inferior colliculus. J Neurophysiol 57:1130-1147. 
Shnciderman A, Oliver DL, Henkel CK (1988) Connections of the dorsal nucleus of the lateral lemniscus: an inhibitory parallel pathway in the ascending auditory system? J Comp Neurol 276:188-208.

Spence CD, Pearson JC (1989) The computation of sound source elevation in the barn owl. In: Advances in neural information processing systems 2 (Touretzky L, ed). San Francisco: Kaufmann.

Stevens SS, Newman EB (1936) The localization of actual sources of sound. Am J Psychol 48:297-306.

Suga N (1988) Parallel-hierarchical processing of biosonar information in the mustached bat. In: Animal biosonar: processes and performance (Nachitgall PE, Moore PB, eds), pp 149-160. New York: Plenum.

Suga N (1989) Principles of auditory information-processing derived from neuroethology. In: Principles of sensory coding and processing (Laughlin SB, ed), pp 277-286. Cambridgc: The Company of Biologists, Ltd.

Sullivan WE, Konishi M (1984) Segregation of stimulus phase and intensity coding in the cochlear nucleus of the barn owl. J Neurosci 4:1787-1799.

Takahashi TT (1988) Commissural projections mediate inhibition in a lateral lemniscal nucleus of the barn owl. Soc Neurosci Abstr 14: 323.

Takahashi TT, Keller CH (1992) Commissural connections mediate inhibition for the computation of interaural level difference in the barn owl. J Comp Physiol [A] 170:161-169.

Takahashi T, Konishi M (1986) Selectivity for interaural time difference in the owl's midbrain. J Neurosci 6:3413-3422.

Takahashi TT, Konishi M (1988a) Projections of the cochlear nuclei and nucleus laminaris to the inferior colliculus of the barn owl. J Comp Neurol 274:190-211.

Takahashi TT, Konishi M (1988b) Projections of nucleus angularis and nucleus laminaris to the latcral lcmniscal nuclear complex of the barn owl. J Comp Neurol 274:212-238.

Takahashi T, Moiseff A, Konishi M (1984) Time and intensity cues are processed independently in the auditory system of the owl. J Neurosci 4:1781-1786.

Takahashi TT, Wagner H, Konishi M (1989) Role of commissural projections in the representation of bilateral auditory space in the barn owl's inferior colliculus. J Comp Neurol 281:545-554.

Van Essen DC, Felieman DJ, DeYoe EA, Olavarria J, Knierim J (1990) Modular and hierarchical organization of extrastriate visual cortex in the macaque monkey. Cold Spring Harbor Symp Quant Biol 55:679696.

Volman SF (1990) Neuroethological approaches to the evolution of neural systems. Brain Behav Evol 36:154-165.

Volman SF, Konishi M (1989) Spatial selectivity and binaural responses in the inferior colliculus of the great horned owl. J Neurosc 9:3083-3096.

Volman SF, Konishi M (1990) Comparative physiology of sound localization in four species of owls. Brain Behav Evol 36:196-215.

Wagner H, Takahashi T, Konishi M (1987) Representation of interaural time difference in the central nucleus of the barn owl's inferior colliculus. J Neurosci 7:3105-3116.

Wise LZ, Frost BJ, Shaver SW (1988) The representation of sound frequency and space in the midbrain of the saw-whet owl. Soc Neurosci Abstr 14:1095.

Wu SH, Kelly JB (1992) Synaptic pharmacology of the superior olivary complex studied in mouse brain slice. J Neurosci 12:3084-3097.

Yin TCT, Hirsch JA, Chan JCK (1985) Response of neurons in the cat's superior colliculus to acoustic stimuli. 2. A model of interaural intensity sensitivity. J Neurophysiol 53:626-645. 